ISSN 0819-2642

ISBN 0734025734

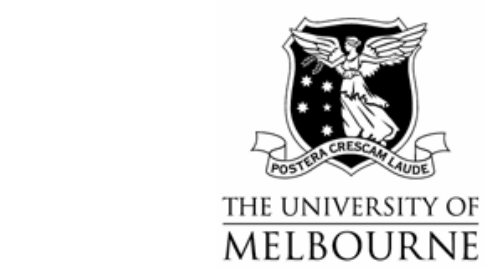

THE UNIVERSITY OF MELBOURNE

DEPARTMENT OF ECONOMICS

RESEARCH PAPER NUMBER 917

SEPTEMBER 2004

\title{
EMISSIONS VARIABILITY IN TRADABLE PERMIT MARKETS WITH IMPERFECT ENFORCEMENT AND BANKING
}

by

Timothy N. Cason

$\&$

Lata Gangadharan

Department of Economics

The University of Melbourne

Melbourne Victoria 3010

Australia. 


\title{
Emissions Variability in Tradable Permit Markets with Imperfect Enforcement and
}

\author{
Banking* \\ Timothy N. Cason \\ Purdue University \\ and \\ Lata Gangadharan \\ University of Melbourne
}

June 2004

\begin{abstract}
Unexpected variation in emissions can have a substantial impact on the prices and efficiency of tradable emission permit markets. In this paper we report results from a laboratory experiment in which subjects participate in an emissions trading market in the presence of emissions uncertainty. Subjects face exogenous, random positive or negative shocks to their emission levels after they make production and emission control plans. In some sessions we allow subjects to bank their unused permits for future use. In all sessions, subjects can trade in a reconciliation period to buy or sell extra permits following the shock realization. Subjects then report their emissions to the regulatory authority and they are placed in different inspection groups depending on their compliance history. The design of our experiment allows us to identify important interactions between emission shocks, banking, compliance and enforcement. We find that the relationship between emission shocks and price changes is significantly stronger without banking, so banking helps smooth out the price variability arising from the imperfect control of emissions. This greater price stability comes at a cost, however, since noncompliance and emissions are significantly greater when banking is allowed.
\end{abstract}

JEL Classification: C91, Q20, D80

Key Words: Emissions Trading, Correlated Shocks, Banking, Laboratory Experiments.

\footnotetext{
* Timothy N. Cason: Department of Economics, Krannert School of Management, 100 S. Grant Street, Purdue University, West Lafayette, IN 47907-2076, USA. Email: cason@mgmt.purdue.edu. Lata Gangadharan: Department of Economics, University of Melbourne, Vic 3010, Australia. Email: latag@unimelb.edu.au. We thank Ashraf Al Zaman for valuable research assistance, and for helpful comments we thank conference and seminar participants at the Iceland Workshop on Experiments in Natural Resource Economics, the Economic Science Association meetings, and Georgia State University. This research has been supported by a grant from the U.S. Environmental Protection Agency's National Center for Environmental Research (NCER) Science to Achieve Results (STAR) program. Although the research described in the article has been funded in part through EPA grant number R829609, it has not been subjected to any EPA review and therefore does not necessarily reflect the views of the Agency, and no official endorsement should be inferred.
} 


\section{Introduction}

Tradable emissions permit programs are being adopted by environmental regulators in a wide variety of applications ranging from local (e.g., ground-level ozone) and regional (e.g., acid precipitation precursors) to a global scale (e.g., international trading of greenhouse gas emissions permits). These innovative programs create incentives for firms to reveal their private marginal valuation from an additional permit, which in turn reveals the firm's private marginal abatement costs. Some of the firms may be able to switch to a pollution-decreasing technology faster or relatively cheaply compared to other firms, or may switch to a different kind of input that generates less pollution. Through emissions trading, firms that can control pollution at a lower cost make the emissions reductions and trading will continue until marginal abatement costs are equalized across firms. When marginal costs are equalized, in theory a given environmental standard is reached at lowest cost. ${ }^{1}$

Many researchers, however, have shown that to realize the maximum benefits from a tradable permit program critical attention must be given to many practical implementation details. Theoretical research has shown that important issues such as the properties and property rights of the permits being traded, the possibility of banking of permits, the transactions costs involved in trading, and the market power of some of the participants must be considered in designing an emissions trading program. Moreover, the cost savings achieved by permit trading are not likely to be realized if compliance with the program is not well-enforced.

Most emissions trading programs are either in their infancy, or are still in the planning or

\footnotetext{
${ }^{1}$ One of the first and most ambitious tradable emissions schemes was the United States Federal $\mathrm{SO}_{2}$ Trading Program (Title IV 1990 Clean Air Act Amendments), which regulates sulfur dioxide emissions that cause acid rain from electricity generation and other industrial sources. Another example is the Regional Clean Air Incentives Market (RECLAIM), established by the South Coast Air Quality Management District in Southern California, which regulates nitrogen and sulfur oxide emissions from industrial sources in the South Coast air basin. Examples of point source water quality trading schemes include the Cherry Creek Basin Trading Program for phosphorous in Colorado (US), and the Hunter River Salinity Trading Scheme, which regulates saline water exports from point sources in New South Wales, Australia. Most of these programs have reported considerable cost savings.
} 
early implementation stage. Consequently, field data to help address these issues remains scarce. To help fill this empirical gap, in this paper we use laboratory methods to examine the interaction of three important issues facing regulators: the impact of banking, uncertainty regarding emissions, and the enforcement and compliance with regulations. We find that the relationship between emission shocks and price changes is significantly stronger without banking, so banking helps smooth out the price variability arising from the imperfect control of emissions. This greater price stability comes at a cost, however, since noncompliance and emissions are significantly greater with banking allowed.

In some permit programs participants can bank their unused permits for future use. Banking allows efficiency gains to be achieved by equalizing (discounted) marginal abatement costs across time. The increased flexibility of banking can also potentially provide an additional source of abatement cost reduction (e.g., see Kling and Rubin, 1997). Cronshaw and BrownKruse (1999) designed experiments to study the features of the permit market initiated under the 1990 US Clean Air Act, and found that subjects were able to achieve about two-thirds of the gains theoretically available from banking alone and an additional $39-78 \%$ of the potential gains when trading was allowed. Godby et al.'s (1997) and Mestelman et al.'s (1999) experiments also indicate that banking helps smooth out the prices of permits. While some emissions trading programs allow unlimited banking (e.g., the federal sulfur dioxide trading program in the United States), others do not allow any banking (e.g., the RECLAIM program in Southern California) while others impose restrictions on the aggregate total of permits that can be banked (e.g., the Ozone Transport Commission in the Eastern United States).

Introduction of uncertainty in demand or in abatement cost technology is another issue that is of interest in tradable permit markets. Ben-David et al. (2000) explore in the laboratory 
the specific effects of uncertainty in tradable permit markets on prices, trading volume and the firms' ability to realize cost savings. They focus on two types of uncertainty: uncertainty regarding the time at which the permit allocation will be reduced and uncertainty regarding the magnitude of the reduction. They find that firms respond to uncertainty by adopting a "wait and see" approach with respect to certain decisions they feel they can feasibly postpone. Hence uncertainty does not lead to decreases in trade volume and ex-ante trading prices are also not affected by uncertainty.

In this paper we introduce uncertainty in the form of random correlated and uncorrelated shocks to the abatement and emissions target specified by the firms. Such variation could occur, for example, due to unexpectedly low production or due to superior abatement equipment performance. Unexpected variation in emissions can also be correlated across firms in many applications. For example, all firms in any particular region would experience similar weather patterns, which would correlate their emissions that are related to energy production. Emissions could also be correlated across firms due to economic growth cycles. During high growth periods, for example, most firms would need more permits. Emissions uncertainty and correlation could thus affect permit prices. Emissions uncertainty also interacts with the choice of banking rules chosen by the regulator. For example, in a model with costly enforcement, Innes (2003) shows that efficient (first-best) regulation of uncertain emissions cannot by achieved without permit banking.

The third feature we examine in this paper is the regulatory compliance strategy followed by firms in an emissions trading market when they are subject to imperfect monitoring by a regulatory agency. Emissions trading with imperfect enforcement has been considered by, among others, Malik (1990) and Stranlund and Dhanda (1999). Continuous emissions 
monitoring is practical for some applications, such as $\mathrm{SO}_{2}$ emissions from large, stationary sources. But in many other applications compliance relies on self-reporting and must be enforced. The only other experimental emissions trading research we are aware of with imperfect enforcement is the recent work by Murphy and Stranlund (2004). They focus on varying the penalty schedules and environmental standard, in a setting in which audit probabilities are unaffected by the individuals' decisions.

Our experiment, by contrast, features a dynamic enforcement strategy in which audit probabilities depend on past compliance and inspections. Economists and policy makers have been puzzled by evidence that most firms comply with environmental regulations, in spite of the fact that the frequency of inspections is not very high in most programs; and even when violations are discovered, fines or penalties are not very severe (e.g., see Eckert, 2004). Static models of regulatory compliance cannot resolve this puzzle, but dynamic models suggested by Harrington (1988), Greenberg (1984) and Landsberger and Meilijson (1982) can. In these dynamic models, the firms that are found to be in violation in one period are moved to a separate group in the next period. In this "high enforcement" group they are subject to more frequent inspection and higher fines. Hence they have an incentive to comply with regulations in order to avoid being moved into this second inspection group. ${ }^{2}$

It is important to examine the interaction among these three features of tradable permit markets. Banking is very useful to minimize unexpected short or long positions at the end of a trading period and therefore reduce uncertainty and risk in the emission market. Allowing for the possibility of correlated random shocks to emissions increases the parallelism between the experiment and the field, and it also allows us to study the impact of these shocks on permit

\footnotetext{
${ }^{2}$ A weakness of this type of conditional audit rule pointed out by Raymond (1999) is that firms' compliance costs must be identical and known to the regulator. Interestingly, these otherwise strong conditions are actually satisfied in competitive permit markets, since marginal compliance costs for all firms equal the (observable) permit price.
} 
prices and on compliance strategies. Earlier research has focused on these issues separately. The impact of emission shocks on prices is significantly stronger when subjects are not allowed to bank permits, so banking clearly helps in stabilizing prices in the permit market. Stability in prices in emissions markets is important for a variety of reasons, including for encouraging the appropriate level of expenditure and R\&D investment on abatement technology. We find that banking, however, leads to lower compliance with regulations. The benefits to underreporting emissions are greater when unused permits can be banked for future use or sale. Regulators therefore would need to consider this tradeoff between the price stability that banking provides and the increase in emissions due to non-compliance.

The rest of the paper is organized as follows. Section 2 describes the experimental design and the procedures followed by the subjects. Section 3 identifies the hypotheses that we test using laboratory data. Section 4 presents the results on compliance behavior of subjects, the emissions generated and the permit prices in the market and section 5 concludes.

\section{Experimental Design}

We conduct 16 sessions, in each of which eight subjects trade emissions permits in a computerized double auction, plan targeted emissions and abatement, and make regulatory reporting and compliance decisions. We use this environmental terminology in describing the experimental design and results, but subjects saw more neutral terminology. For example, we called emissions permits simply "coupons," and we referred to marginal abatement costs as marginal "production costs." See the instructions in the appendix for details. Table 1 summarizes the essential components of the experimental design. We conducted the experiment using the 
University of Zurich's Z-tree program (Fischbacher, 1999). All subjects were undergraduate students at Purdue University.

Subjects participate in a randomly determined number of periods that is unknown to them. Each period is divided into different stages. In some stages subjects trade emission permits and in other stages they are required to plan abatement and report emissions. Subjects can "legally" avoid incurring abatement costs by holding and redeeming emissions permits. All subjects start stage 1 of each period with a number of permits determined by an initial allocation, adjusted upward by previous period banking or downward by enforcement penalties. They can then adjust their permit holdings by buying and selling in the double auction permit market. ${ }^{3}$ The first stage market is open for trading for 3 minutes. Marginal abatement costs and the initial permit endowment varied across subjects as shown in Table 2, providing gains from trade. Figure 1 displays the aggregate demand (derived from the avoided abatement costs) and aggregate supply of permits in period 1. For the aggregate endowment of 32 permits, prices in the interval $[88,91]$ clear the market.

In stage 2 subjects enter an abatement target. Their actual abatement, however, and therefore realized emissions, could differ from the target specified by a random shock. Actual abatement is equal to the target abatement plus the random shock, which can be $-2,-1,0,1$, or 2 . This simple distribution is easy for subjects to understand, and it is similar to the shocks used by Godby et al. (1997), except that Godby et al. employed a smaller range of $-1,0$ or 1 . In one of the treatments examined in this paper, we focus on the correlation of the shocks experienced by

\footnotetext{
${ }^{3}$ The continuous double auction market is commonly used in economics experiments to generate a competitive trading environment with relatively accurate and rapid price discovery. Both sellers and buyers are free to submit public offers to sell or buy at any time, or to accept an offer and immediately execute a transaction. We employ an order improvement rule, requiring new buy offers to exceed the current best buy offer and requiring new sell offers to be less than the current best sell offer. The zTree program we use immediately updates traders' portfolios following a transaction, and it maintains a public order book of buy and sell offers. We restrict all trades and offers to one permit at a time.
} 
subjects. In 8 of the sessions subjects face uncorrelated random shocks, and in the other 8 sessions subjects face correlated random shocks. Uncorrelated shocks imply that the five possibilities $(-2,-1,0,1,2)$ are equally likely, and independently drawn across subjects. In the sessions with correlated shocks, there is an equal chance each period that everyone has nonpositive or nonnegative shocks; i.e., all shocks are either iid of $(-2,-1,0)$ with probabilities $(40 \%, 40 \%, 20 \%)$ or are iid over $(0,1,2)$ with probabilities $(20 \%, 40 \%, 40 \%)$. Positive abatement shocks lead to lower levels of realized emissions and can thus be interpreted as negative emission shocks. Similarly negative abatement shocks are similar to positive shocks to emission levels.

In stage 3 subjects learn about the amount and direction of their random shock and hence their actual abatement and emissions level. Then the permit market is opened for trade for another 2 minutes. Emissions trading programs in the field frequently feature this type of reconciliation period for trading following the conclusion of the control period and the realization of actual emissions. The price impact of the emissions shocks is likely to be strongest during this reconciliation period. Another treatment in this paper focuses on banking. In 8 sessions subjects are allowed to carry forward their unused permits to the next period, and in the remaining 8 sessions any unused permits expire and cannot be banked.

The regulator always perfectly observes the number of permits held by each subject, as would be the case, for example, with a well-designed permit registry. Emissions are selfreported, however, to an "inspector" in the last stage of each period, stage 4. Following this report, the inspector randomly determines whether to inspect the firm to determine actual emissions. If the subject is inspected, the inspector observes the actual emissions and also whether the abatement and emissions report submitted by the subject is truthful. If the actual 
abatement + permits sum is less than 10 , then subjects pay a fine for each unit below 10 , and the permits they start the next period with are reduced by the amount that this sum falls below $10 .{ }^{4}$ If this sum is greater than 10 , then they are not fined and in sessions where banking is allowed, they can carry over these "unused" permits to the next period. Subjects are also fined if their abatement report $>$ actual abatement, and they pay a fine for each unit that these amounts differ. They pay the maximum fine calculated by these two methods. If the subject is not inspected, the inspector just checks whether the abatement report + permits $\geq 10$. If this sum is less than 10 , then this subject would pay a fine for each unit below 10 , and the permits she starts the next period with are reduced by the amount the sum falls below 10. If this sum is greater than 10 , then she is not fined and can carry over these "unused" permits to the next period.

Based on the dynamic enforcement, conditional audit model of Harrington (1988), our enforcement regime employs two inspection groups. If the subject pays a fine for any type of violation while in group 1 , she is automatically moved to group 2 . If she is inspected while in group 2 and is found to be in full compliance, then she is automatically moved back into group 1. Everyone starts the experiment in group 1. The chances of being inspected and the per-unit fines for violations differ in the two groups. In group 1, subjects are inspected with a probability of 0.3 and if caught violating they are fined 60 for each unit of violation and they are moved to group 2 , which has a higher inspection probability (0.5) and a higher per-unit fine for violating (150). These inspection rates and fines do not change during the experiment. Although the expected per-unit penalty in group 2 is only $75(150 \times 0.5)$, the enforcement leverage provided by the two inspection groups makes full compliance optimal for subjects in this group even when permit prices (i.e., the marginal compliance cost) rise as high as 132 .

\footnotetext{
${ }^{4}$ Reducing the following period's permit allocation is a common penalty in emissions trading markets.
} 
The end period of the experiment is determined randomly. Subjects know that 8 periods are conducted with certainty in each session, and then after the $8^{\text {th }}$ period and after every subsequent period the experimenter rolls a 6-sided die. If this die roll comes up " 6 " then the experiment ends immediately; otherwise, the session continues for another period. The experimenter reveals the outcome of each single roll at the end of each period beginning after the $8^{\text {th }}$ period. A total of 11-17 periods were conducted in each session.

In all 16 sessions reported here subjects were experienced as they had participated in a training session where they made decisions relating to compliance and also participated in up to 5 periods of the 4-stage permit trading environment just described, but with different parameters. These training periods are not reported here, but Cason and Gangadharan (2004) reports an analysis of the compliance training data in which subjects participated in 7 separate treatments with different compliance costs and enforcement parameters. Prior to the sessions reported here, the experimenter reviewed the instructions and conducted a quiz that the subjects needed to answer before participating in the experiment. We implemented a balanced $2 \times 2$ design, with 4 sessions in each of the 4 treatment conditions (banking versus no banking, and correlated versus uncorrelated emission shocks). One session in each treatment employed double-experienced subjects who had already participated in one full session. At the end of each session, Experimental dollars were converted to U.S. Dollars, at a rate of 300 Experimental Dollars $=1$ U.S. Dollar. Including instruction time, sessions lasted about 2 hours, and the subjects earned an average of $\$ 26.42$ per person.

\section{Hypotheses}

This experimental design allows us to address several principle hypotheses. The first 4 
concern compliance behavior of agents when reporting emissions.

Hypothesis 1: Noncompliance is greater for agents in inspection group 1.

Hypothesis 2: Noncompliance is greater when permit prices are higher.

Hypothesis 3: Noncompliance is not greater for agents who face greater marginal abatement costs.

Hypothesis 4: Noncompliance is greater following positive aggregate and individual shocks to emissions.

The first two hypotheses follow directly from an application of Harrington's (1988) model of enforcement leverage. Permit prices determine the marginal compliance cost for all firms, because any firm could achieve compliance by acquiring permits. Of course, in equilibrium the permit price equals the marginal abatement cost that is equalized across firms. For the enforcement parameters employed in the experiment, for all marginal compliance costs (permit prices) in the interval $(18,132)$ the optimal compliance policy is to violate in inspection group 1 and comply in inspection group 2. Subjects should comply in all inspection groups for prices less than 18 and they should never comply in any inspection group for prices greater than $132 .^{5}$ Most prices were in the $(18,132)$ interval, although a few were greater than 132. Therefore, we expect significantly more noncompliance for subjects when they are in group 1 .

In theory the threshold permit price of 132 is a critical point where noncompliance should increase significantly. In previous work that manipulated compliance costs and enforcement parameters across a variety of treatments, Cason and Gangadharan (2004) found that noncompliance rates increased gradually as the relative payoff to noncompliance increased,

\footnotetext{
${ }^{5}$ As already mentioned, the end period of the experiment is randomly determined. However, in periods 1-7 before the die rolls begin, subjects know that a minimum number of additional periods will be conducted with certainty. This raises the maximum permit price for which the "violate in group 1 and comply in group 2" strategy is optimal, effectively increasing the range of prices for which this compliance policy should be adopted.
} 
rather than a sharp switch from one corner solution to the other when compliance costs passed through the critical threshold. This earlier study employed a quantal choice model of bounded rationality that can fit this compliance pattern accurately. Correspondingly, we expect a more smooth adjustment of compliance rates to permit prices, indicated by Hypothesis 2 .

Hypothesis 3 follows from Stranlund and Dhanda (1999), who point out that unlike traditional models of regulation in which individual compliance costs determine incentives for compliance, when emissions permits are tradable the permit price represents the marginal compliance cost that is relevant for all agents' compliance decisions. Therefore, we expect that even though our subjects faced significantly different (pre-trade) marginal abatement costs, they should not comply at significantly different rates since they could all obtain permits at the same price on the market.

Hypothesis 4 postulates a relationship between emissions shocks and compliance, operating indirectly through permit prices, and it is related to Hypothesis 2. Positive emissions shocks are likely to increase permit prices, increasing compliance costs and decreasing compliance. But if the shocks are not fully reflected in permit prices, some subjects facing positive, idiosyncratic shocks may not be able to acquire sufficient permits in the reconciliation period and may be noncompliant.

The next hypothesis concerns the environmental performance of the system, and is the emissions counterpart to Hypotheses 2:

Hypothesis 5: Emissions are greater when permit prices are higher.

We expect that emissions will be significantly greater when permit prices are higher, if (according to Hypothesis 2) the higher prices cause more agents to be noncompliant.

The final hypotheses concern permit prices: 
Hypothesis 6: Permit prices are less volatile when permits can be banked for future use.

Hypothesis 7: Permit prices are higher on average, particularly late in the period, following positive (aggregate) shocks to emissions. This relationship between emissions shocks and permit prices is stronger without permit banking.

Hypothesis 8: Permit prices are lower on average when more permits were banked in the previous period.

Hypotheses 6 and 7 are closely related. When positive (negative) aggregate emissions shocks occur, agents require more (fewer) permits than they had planned. This puts upward (downward) pressure on permit prices in the reconciliation trading period. If agents cannot bank permits, unused permits expire and become worthless when the period ends. Therefore, prices could plummet following negative emissions shocks and sellers dump unneeded permits on the market. The inability to bank permits can also result in price spikes following positive emissions shocks. Because of the permit expiration, agents do not wish to hold a large "buffer" of permits to insure them against positive emission shocks. Consequently, when those shocks do occur, an overall shortage of permits exists, driving up their price.

Banking allows agents to hold a buffer of permits to insure against price spikes, and it also eliminates their incentive to dump unused permits on the market. As more permits are banked, however, this can affect price levels. In particular, Hypothesis 8 indicates that greater banking is expected to result in lower permit prices, since banking effectively increases the supply of available permits. This is analogous to shifting out the vertical supply of permits on Figure 1 above. 


\section{Results}

In this environment with emissions shocks and imperfect enforcement, allowing banking of permits leads to a reduction in permit price volatility, but banking also reduces compliance and increases emissions. Figures 2 and 3 illustrate the price volatility effects, which are formally documented later in Section 4.2. These figures also help the reader understand the price data generated by the experiment. The vertical lines represent breaks between periods. Figure 2 displays transaction prices in session BUN3, which features permit banking and uncorrelated emissions shocks. Prices are relatively stable at approximately 80 experimental francs. This is a bit lower than the initial market-clearing price interval of 88-91, but prices should decline when the stock of banked permits increases above zero (as occurs in this and most other sessions with banking). Figure 3 displays transaction prices in session NBCO3, which features no permit banking and correlated emissions shocks. The large price volatility in this session is striking, particularly the late period trades after the emissions shocks are realized. Low prices late in the period, such as indicated in periods 3, 4 and 13, follow negative emissions shocks that cause the unbankable permits' value to plummet. High prices late in the period, such as in periods 8 and 11, follow positive emissions shocks that lead to a shortage due to the limited available permits.

\subsection{Compliance and Emissions}

Recall that emissions permit trading equalizes the cost of compliance across firms, since the market price of permits determines marginal compliance costs. Recall also that for the twostate enforcement program and the fines, inspection rates and group transition probabilities chosen for our experiment, traders should violate when in inspection group 1 and comply when in inspection group 2 for prices in the interval $(18,132)$. The vast majority of prices are in this interval, and for some sessions this interval contains all transaction prices. Compliance is optimal 
in both inspection groups for lower prices, and violation is optimal in both inspection groups for higher prices.

Table 3 presents the average compliance rates for each of the 16 sessions. Panel A displays the rates for both inspection groups pooled, Panel B displays the rates for subjects when in inspection group 1, and Panel C displays the rates for subjects when in inspection group 2. The pooled rates in Panel A suggest that compliance rates are lower when permit banking is allowed (the left column), but the difference between banking and no banking is not quite statistically significant when using a very conservative, nonparametric Wilcoxon signed-rank test (two-tailed $p$-value $=0.176$ ). This and all subsequent Wilcoxon tests employ exactly one summary statistic value per session, in order to satisfy the statistical independence required for this test.

The compliance rates for subjects within inspection group 1 (Panel B) are significantly different across the banking treatments, however, using this same Wilcoxon test (two-tailed $p$ value $=0.039)$. More subjects—about half overall—fail to comply in this inspection group when they can bank any permits that they do not submit to cover reported emissions. Closer to twothirds of subjects comply in this group when they cannot bank permits. Compliance rates are not significantly different in inspection group 2 (Panel C) with or without banking. Compliance rates are significantly higher when in group 2 than when in group 1 , however (Wilcoxon two-tailed $p$ value $=0.018$ ). This provides our initial support for Hypothesis 1. Compliance rates are not significantly different for correlated versus uncorrelated emissions shocks for any of the panels of Table 3.

These conservative, nonparametric tests are valuable because they require a minimum of statistical assumptions, and because they are based on only statistically independent observations. They cannot address all research questions of interest, however. For example, 
Hypotheses 2 predicts a relationship between compliance rates and permit prices. It is not clear from Table 3 whether the significantly lower compliance rate with banking allowed is due to higher prices with banking or some other factor, such as differences in the random emissions shocks across treatments. The contributions of the (potential) multiple influences on compliance can only be evaluated using multivariate regression models.

Table 4 presents such an analysis of the compliance choices of subjects. These panel regressions employ a random effects error structure, with the subject representing the random effect. The empirical models allow compliance to depend on the amount the individual banks in the previous period, which inspection group the individual is in when she enters the new period, the banking dummy ( $=1$ in sessions where banking is allowed), the correlated shocks dummy ( $=1$ in sessions where the shocks are correlated across all subjects), the magnitude of the emissions shocks experienced by the individual (defined as the difference between the target emissions and the actual emissions realized), the magnitude of the total shocks faced by all the subjects in that period, and on the price of permits. The price of permits is endogenous, as higher compliance rates could increase the average permit prices in the post shock trading stage. We therefore estimate a price equation based on only exogenous variables and use the predicted price from this estimation in the compliance equation, the standard instrumental variables technique. (Price equation, with post shock transaction prices as the dependent variable, R-squared $=0.33$, observations: 1384).

Columns 1 and 2 of Table 4 present results from a random effects probit model for the compliance choices. The probit model examines the factors that determine the subjects' binary decision to comply with or violate regulations. The model specification in column 2 includes the marginal abatement costs faced by subjects to examine if higher marginal abatement costs lead to 
lower compliance performance. ${ }^{6}$ The probability of compliance is significantly higher when subjects are in inspection group 2, providing further support for Hypotheses 1. The marginal effects on the probit regression indicate that being in inspection group 2 increases the probability of compliance by 28 percent. $^{7}$ The probability of compliance decreases when subjects experience higher individual and total shocks to emissions, supporting Hypotheses 4. Notably, the individual shock is an order of magnitude more important than the aggregate shock experienced by the market. A one-unit increase in the individual shock decreases the probability of compliance by 7 percent whereas the same change in the aggregate shock decreases compliance by only 0.8 percent. These shocks decrease the supply of permits in the market, thus increasing permit prices and decreasing the level of compliance. In sessions with banking, the probability of compliance is lower by 11 percent.

The likelihood of compliance is also significantly lower when permit prices are higher, supporting Hypothesis 2. The marginal abatement cost of the individual is also significant, however, with higher costs reducing the probability of compliance. But the impact of this variable is not very strong, which provides evidence for Hypothesis $3 .{ }^{8}$ The impact of prices on compliance is approximately four times stronger than the marginal cost effect. The marginal

\footnotetext{
${ }^{6}$ There are 4 types of subjects in the experiment, with two subjects in each type. The marginal abatement cost variable takes a value of 145 for type 1 subjects, 119 for type 2 subjects, 73 for type 3 subjects and 54 for type 4 subjects. We also conducted robustness tests by including a dummy for high marginal abatement cost and this dummy is not significant in explaining compliance.

${ }^{7}$ These marginal results are not presented in the table.

${ }^{8}$ The marginal abatement cost loses its significance in explaining compliance when we include an additional explanatory variable (net seller) to capture the initial endowment of permits of the subjects. Four of the subjects are net sellers of permits as their initial endowment is larger than what they should retain given the market price of permits. The other four subjects are net buyers. Murphy and Stranlund (2004) report that their net sellers have significantly higher compliance levels than their net buyers. In our data we find that being a net seller does not lead to greater compliance. Hence neither the initial endowment nor marginal abatement costs of subjects can predict compliance as accurately as can the price of permits.
} 
abatement cost of the individuals provides little extra information, beyond permit prices, to better predict compliance behavior. $^{9}$

Columns 3 and 4 of Table 4 present estimates from a random effects tobit model on the magnitude of violation. The tobit model accounts for the lower threshold of zero for the amount violated. The results mirror those from the probit model and show that the amount of noncompliance is significantly higher when banking is allowed. Higher permit prices later in the period also increase the amount violated. Note that marginal abatement costs do not have a significant impact on compliance in the tobit model.

Compliance rates alone may not be the most important measure of system performance, because a regulator might not be concerned about lower compliance unless it led to higher emissions. Our data strongly establish this inverse relationship between compliance and emissions. Table 5 presents the average emissions for each of the 16 sessions. Recall that the target emissions - the number of issued permits - is 32 per period. Actual emissions exceed this target on average in all 8 sessions with banking allowed, but in only one-half of the sessions without banking. Using the Wilcoxon test based on one observation per session, these data reject the hypothesis that average emissions rates are the same with and without banking (two-tailed $p$ value $=0.048$ ). Emissions are not significantly different for the two types of shock correlation.

Table 6 presents a random effects regression model of emissions to determine the factors that affect the total amount of emissions generated by the subjects in each period. The sixteen sessions represent the random effect in this panel. The estimates show that an additional permit

\footnotetext{
${ }^{9}$ Murphy and Stranlund (2004) vary the enforcement level and separate out the direct and indirect price impact of increased enforcement on compliance behavior. They show that increased enforcement encourages firms to increase their compliance levels by purchasing more permits (direct effect). This however puts upward pressure on prices in the permit market and eventually leads to less compliance by firms (indirect effect). The direct effect is always larger so that increased enforcement leads to higher compliance levels, however the indirect price effect is often significant and ignoring it could over-estimate the effectiveness of enforcement programs. Our experiment does not vary the enforcement parameters and so it does not trace out these direct and indirect effects.
} 
banked and carried forward to the current period leads to a 0.5 increase in total emissions. The positive and highly significant coefficient for the aggregate shocks indicates that an increase in the magnitude of aggregate shocks to the market increases emissions by 0.96 . Transaction prices do not significantly increase market-level emissions in this model, providing no support for Hypothesis $5 .^{10}$

\section{$\underline{4.2}$ Permit Prices}

Figures 2 and 3 highlight the implications of our banking and emissions shock correlation treatment variables on price volatility for some individual sessions. We formally document those implications here. First, however, consider Figures 4 and 5, which display one data point for each period in each session. The vertical axis is the difference in average transaction prices before and after the emissions shock is realized, and the horizontal axis is the aggregate (summed across all traders) level of the emissions shock. The observations for the correlated shocks, shown with solid squares, typically have greater (absolute) shocks due to the shock correlation. As expected, in both Figures 4 and 5 a positive relationship exists between the emissions shock and the change in transaction prices, with a greater emissions shock usually associated with a larger price increase.

More importantly, a comparison between these two figures indicates a much stronger relationship between shocks and price changes for the sessions without banking than for sessions with banking allowed. When banking is allowed (Figure 4) average prices usually change following the shock by less than 20 experimental francs. Without banking (Figure 5), average prices frequently change by more than 20 francs, and sometimes by as much as 60 francs. The

\footnotetext{
${ }^{10}$ The perceptive reader may have noticed that we do not report a standard efficiency measure of overall system performance. This is because overall efficiency depends on the social cost of emissions. Since emissions frequently exceed the per-period target of 32, our realized efficiency depends on the environmental damage function, which is not specified in the experiment.
} 
regression lines fit through these data points also indicate a much stronger (linear) relationship between shocks and price changes for the no banking treatment. The $\mathrm{R}^{2}$ statistics indicate that nearly two-thirds of the price change can by explained by the abatement shock without banking, compared to only about one-quarter that can be explained by the abatement shock when banking is allowed.

Table 7 presents the average absolute difference in average prices before and after the emissions shock is realized, separately for all 16 sessions. A Wilcoxon test based on these 16 independent observations strongly rejects the null hypothesis that these differences are equal in the banking and in the no banking treatments (two-tailed $p$-value=0.011). In fact, only the lowest no banking average difference (7.63) is lower than any of the 8 differences with banking allowed. This provides strong support for Hypothesis 6. The differences also appear greater on average when emission shocks are correlated than when they are uncorrelated, but these differences are not quite significant (two-tailed $p$-value=0.177).

Table 8 shows an alternative measure of price volatility that does not distinguish the preand post-shock trading periods. It reports the average coefficient of variation in transaction prices, calculated based on all transaction prices within a period regardless of when they take place. A Wilcoxon test based on these 16 observations also strongly rejects the null hypothesis that the average coefficient of variation is equal in the banking and in the no banking treatments (two-tailed $p$-value $=0.007$ ), but it does not reject the null hypothesis that the average coefficient of variation is equal in the correlated and uncorrelated emissions shocks treatments. This provides further evidence to support Hypothesis 6.

Average transaction prices vary across sessions due to levels of banking and the presence of emissions shocks. Table 9 documents some parametric evidence on these price movements 
using random effects panel regressions, with the session representing the random effect. Column 1 presents results when the dependent variable is the average price for the trades that occur before the emission shock, column 2 when the dependent variable is the average of all transaction prices, and column 3 when the dependent variable is the average of the post shock (reconciliation period) transaction prices. The impact of the aggregate shocks is clear from this table and provides support for Hypotheses 7. Positive emissions shocks lead to a significant increase in post shock prices (column 3) and have no impact on the early period prices and the overall prices. The interaction between the shocks and banking is also evident. In sessions where banking is not allowed, the post shock transaction prices increase by 2.4 additional experimental dollars on average for each unit of the shock, compared to the case when banking is allowed. Banking permits in the previous period reduces the transaction prices significantly in the current period and this is irrespective of whether the early, the late or the overall prices are employed as the dependent variable. This provides evidence supporting Hypothesis 8 . The magnitude of the impact of banking is, however, highest for the late period prices, with an additional banked permit reducing post shock prices by 0.94 experimental dollars. This is significantly different from the average change in the marginal abatement cost function per unit -i.e., the average slope in the Figure 1 aggregate marginal abatement cost curve - of 1.70.

\section{Conclusion}

The economic and environmental gains expected from emissions trading programs depend on how these programs are implemented in the field. In this paper we focus on three design details relevant for permit market performance: the effect of allowing permit banking, the 
impact of uncertainty regarding emissions, and the incentives to comply with regulations. Although there is some empirical work on the relevance of banking in permits markets and the impact of imperfect enforcement, to our knowledge this paper is the first to examine the interaction between banking, emissions shocks and compliance. This can provide the first steps towards designing more optimal permit market regulations to achieve emissions targets with limited enforcement budgets and imperfect compliance.

Using laboratory methods we find that banking helps in smoothing out the price volatility arising from the uncertainty over emissions. Price stability is important to equalize marginal abatement costs across firms and to provide the appropriate incentives for $R \& D$ into new emission control technologies. Allowing subjects to bank permits, however, leads to less compliance, and emissions are significantly higher with banking. The role of banking in promoting noncompliance is somewhat puzzling, since subjects could oversell permits within the current period and not comply. It is not necessary to bank permits to not comply, but our subjects more frequently chose to underreport emissions at the end of the period when they could bank permits. Our laboratory subjects apparently perceived that the benefits of underreporting emissions are greater when banking is allowed, since unused permits can be carried over and used or sold in subsequent periods. Such incentives seem under-appreciated in the literature; for example, in Innes' (2003) model banking reduces noncompliance and therefore economizes on enforcement costs. Our results therefore highlight an important tradeoff between price volatility and noncompliance that regulators need to consider when designing an emission permit program with imperfect enforcement. More research is needed, however, to better understand the incentives for noncompliance in the presence of banking. 
Other banking rules may provide different compliance incentives, and they could be investigated in future theoretical and empirical work. For example, as noted in the introduction the Ozone Transport Commission in the Eastern U.S. restricts the aggregate level of banking to limit the year-to-year variability in emissions. In particular, if the total amount of banked emissions (by all sources) exceeds 10 percent of the total allowable emissions for the year, a 2for-1 discount is applied to the use of the extra banked allowances. This could reduce the benefits of banking and increase incentives for compliance, relative to the unlimited banking studied in the present paper. We believe this is an interesting direction for future work. 
Table 1: Summary of the Experimental Environment

- $\quad$ Subjects

- Undergraduate students all of whom participated in a training session before participating in the data sessions.

- 8 subjects in each session. There are 4 types of subjects in each session, with 2 in each type. The types differ by the marginal abatement costs (see Table 2).

- Sessions

○ 16 sessions, with 11-17 periods in each session. The end period is determined randomly.

$\circ$ Each period is divided into four stages.

- Treatments

- Banking of permits: banking allowed in half of the sessions, and not allowed in the other half.

- Shocks to emissions: correlated shocks in half of the sessions and uncorrelated shocks in the other half.

- A balanced $2 \times 2$ design, with 4 sessions in each of the 4 treatment conditions.

- $\quad$ Stage 1: Permit Trading

- Subjects start this stage with an initial allocation of permits that is adjusted upward if banking is allowed in that session or downward due to enforcement penalties.

- Subjects can buy or sell permits in a double auction permit market.

- 3 min trading period.

- Stage 2: Abatement target

- Subjects enter an abatement target.

- Their actual abatement however could be lower or higher by a random amount which is revealed to them at the start of stage 3 .

- Stage 3: Actual Abatement and Reconciliation Market

- Subjects learn about the random shock that they face.

$\circ$ This random shock can be $-2,-1,0,1,2$.

- In 8 of the sessions subjects face correlated random shocks: i.e., all shocks are either iid drawn from $(-2,-1,0)$ with probabilities $(40 \%, 40 \%, 20 \%)$ or are iid drawn from $(0,12)$ with probabilities $(20 \%, 40 \%, 40 \%)$.

- In 8 sessions subjects face uncorrelated shocks: i.e., the five possibilities $(-2,-1,0,1,2)$ are equally likely, drawn iid.

- After they learn about their actual abatement, the market is open for trading for 2 minutes.

- $\quad$ Stage 4: Reporting Emissions

- Subjects report emissions.

$\circ$ To be in compliance subjects must have the sum of abatement plus permits $>=10$.

- If not compliant they pay a per unit fine and their permits for next period are reduced by the amount the sum falls below 10 .

- Also if the actual and reported abatement does not match, subjects pay a fine.

- Enforcement

○ Dynamic framework: audit probability depends on past compliance and inspections.

- 2 inspection groups. Subjects start the experiment in group 1.

- If subjects pay a fine for any violation, they are moved to group 2 where they are inspected more frequently and have to pay a higher fine for violations.

- If subjects are inspected in group 2 and found compliant, they are moved back to group 1 . 
Table 2: Assigned Marginal Abatement Costs

\begin{tabular}{ccccc}
\multicolumn{5}{c}{ Marginal Abatement Costs } \\
\hline $\begin{array}{c}\text { Units of } \\
\text { Abatement }\end{array}$ & $\begin{array}{c}\text { Type 1 } \\
\text { (firms 1-2) }\end{array}$ & $\begin{array}{c}\text { Type 2 } \\
\text { (firms 3-4) }\end{array}$ & $\begin{array}{c}\text { Type 3 } \\
\text { (firms 5-6) }\end{array}$ & $\begin{array}{c}\text { Type 4 } \\
\text { (firms 7-8) }\end{array}$ \\
\hline 1 & 53 & 67 & 27 & 35 \\
2 & 61 & 70 & 35 & 38 \\
3 & 70 & 74 & 44 & 42 \\
4 & 80 & 79 & 53 & 47 \\
5 & 91 & 86 & 63 & $\mathbf{5 4}$ \\
6 & 103 & 95 & $\mathbf{7 3}$ & $\mathbf{6 3}$ \\
7 & 116 & 106 & $\mathbf{8 4}$ & $\mathbf{7 4}$ \\
8 & 130 & $\mathbf{1 1 9}$ & $\mathbf{9 8}$ & $\mathbf{8 8}$ \\
9 & $\mathbf{1 4 5}$ & $\mathbf{1 3 4}$ & $\mathbf{1 1 3}$ & $\mathbf{1 0 5}$ \\
10 & $\mathbf{1 6 1}$ & $\mathbf{1 5 1}$ & $\mathbf{1 2 9}$ & $\mathbf{1 2 5}$ \\
Permit Endowment: & 2 per firm & 3 per firm & 5 per firm & 6 per firm \\
\hline \hline
\end{tabular}

Note: Permit endowment, pre-trading, allows firms to avoid the abatement costs shown in bold. 
Table 3 (continued): Average Compliance Rates for 16 Individual Sessions

Panel C: Inspection Group 2 Only

Uncorrelated Emission Shocks

Sessions Banking Allowed No Banking

$\begin{array}{lll}\text { BUN1 \& NBUN1 } & 0.89 & 0.58\end{array}$

BUN2 \& NBUN2 $\quad 0.53 \quad 0.81$

BUN3 \& NBUN3 $\quad 0.93 \quad 0.70$

BUN4 \& NBUN4 $\quad 0.83 \quad 0.89$

\begin{tabular}{lll} 
Treatment Mean & 0.80 & 0.75 \\
\hline
\end{tabular}

Correlated Emission Shocks

Sessions Banking Allowed No Banking

$\mathrm{BCO} 1 \& \mathrm{NBCO} 1 \quad 0.91 \quad 0.63$

$\mathrm{BCO} 2 \& \mathrm{NBCO} 2 \quad 0.42 \quad 0.53$

$\mathrm{BCO} 3 \& \mathrm{NBCO} 3 \quad 0.81 \quad 0.71$

BCO4 \& NBCO4 $\quad 0.75 \quad 0.81$

\begin{tabular}{lll} 
Treatment Mean & 0.72 & 0.67 \\
\hline
\end{tabular} 
Table 4: Random Effects Models on Compliance Decisions

\begin{tabular}{|c|c|c|c|c|}
\hline \multirow{2}{*}{ Explanatory Variables } & \multicolumn{2}{|c|}{ Probit(=1 if comply) } & \multicolumn{2}{|c|}{ Amount of Violation (Tobit) } \\
\hline & Model 1 & Model? & Model 1 & Model 2 \\
\hline \multirow{2}{*}{ Amount Individually Banked } & 0.0100 & 0.0093 & -0.0034 & -0.0009 \\
\hline & $(0.0196)$ & $(0.0198)$ & $(0.0477)$ & $(0.0467)$ \\
\hline \multirow[t]{2}{*}{ Inspection Group 2 Dummy } & $1.4438 * *$ & $1.4530 * *$ & $-4.1411 * *$ & $-4.1746^{* *}$ \\
\hline & $(0.1402)$ & $(0.1408)$ & $(0.3207)$ & $(0.3321)$ \\
\hline \multirow[t]{2}{*}{ Dummy for Banking } & $-0.5520 *$ & $-0.4984 *$ & $1.5902 * *$ & $1.8024 * *$ \\
\hline & $(0.2435)$ & $(0.2294)$ & $(0.5465)$ & $(0.5624)$ \\
\hline \multirow[t]{2}{*}{ Dummy for Correlated Shocks } & -0.0680 & -0.0148 & -0.3016 & -0.1384 \\
\hline & $(0.2362)$ & $(0.2315)$ & $(0.5049)$ & $(0.5456)$ \\
\hline \multirow[t]{2}{*}{ Amount of Individual Shocks } & $-0.3392 * *$ & $-0.3426 * *$ & $0.9012 * *$ & $0.9060 * *$ \\
\hline & $(0.0506)$ & $(0.0503)$ & $(0.1214)$ & $(0.1220)$ \\
\hline \multirow[t]{2}{*}{ Amount of Aggregate Shocks } & $-0.0395 * *$ & $-0.0389 * *$ & $0.0972 * *$ & $0.0977 * *$ \\
\hline & $(0.0143)$ & $(0.0141)$ & $(0.0342)$ & $(0.0338)$ \\
\hline \multirow[t]{2}{*}{ Post-Shock Transaction Price ${ }^{+}$} & $-0.0199 * *$ & $-0.0201 * *$ & $0.0456^{* *}$ & $0.0458 * *$ \\
\hline & $(0.0055)$ & $(0.0054)$ & $(0.0127)$ & $(0.0127)$ \\
\hline \multirow[t]{2}{*}{ Marginal Abatement Cost } & & $-0.0052 *$ & & 0.0065 \\
\hline & & $(0.0030)$ & & $(0.0064)$ \\
\hline \multirow[t]{2}{*}{ Constant } & $2.3901 * *$ & $2.8546^{* *}$ & $-5.4188 * *$ & $-6.3299 * *$ \\
\hline & $(0.5567)$ & $(0.6110)$ & $(1.3586)$ & $(1.6543)$ \\
\hline Observations & 1274 & 1274 & 1274 & 1274 \\
\hline Number of subjects & 128 & 128 & 128 & 128 \\
\hline
\end{tabular}

Standard errors in parentheses

Denotes $*$ significant at $5 \%$; $*$ significant at $1 \%$

${ }^{+}$Instrumental variable (predicted value from the price regression used) 
Table 5: Average Emissions for 16 Individual Sessions

\begin{tabular}{lcc}
\hline \hline \multicolumn{3}{l}{ Uncorrelated Emission Shocks } \\
Sessions & Banking Allowed & No Banking \\
BUN1 \& NBUN1 & 38.76 & 30.18 \\
BUN2 \& NBUN2 & 35.82 & 38.64 \\
BUN3 \& NBUN3 & 34.92 & 31.92 \\
BUN4 \& NBUN4 & 46.09 & 35.91 \\
\cline { 2 - 3 } Treatment Mean & 38.90 & 34.16 \\
\hline \hline Correlated Emission Shocks & \\
Sessions & Banking Allowed No Banking \\
BCO1 \& NBCO1 & 36.82 & 29.55 \\
BCO2 \& NBCO2 & 43.55 & 29.73 \\
BCO3 \& NBCO3 & 42.08 & 34.00 \\
BCO4 \& NBCO4 & 37.36 & 39.91 \\
\cline { 2 - 3 } Treatment Mean & 39.95 & 33.30 \\
\hline \hline
\end{tabular}

Note: Emissions target is 32 units.

Table 6: Random Effects Regression on Aggregate Market Level Emissions

\begin{tabular}{lc}
\hline \hline Explanatory Variables & $\begin{array}{c}\text { Estimate } \\
\text { (Standard Error) }\end{array}$ \\
\hline Post-shock Transaction Prices ${ }^{+}$ & 0.0277 \\
Dummy for Banking & $(0.0573)$ \\
& 1.9949 \\
Amount Banked and Brought Forward & $(2.6312)$ \\
& $0.4964 *$ \\
Magnitude of Aggregate Shocks & $(0.0783)$ \\
& $0.9612 * *$ \\
Constant & $(0.1273)$ \\
& $32.1056^{* *}$ \\
Observations & $(5.6705)$ \\
Number of sessions & 188 \\
\hline \hline Standard errors in parentheses & 16 \\
Denotes $*$ significant at 5\%; $*$ significant at 1\% & \\
+ Price instrumented for, to correct for endogeniety (First stage Price regression: Observations \\
$=188$, Wald Chi 5 ) $=164$, Prob $>$ Chi squared $=0.0000)$
\end{tabular}


Table 7: Average Absolute Price Difference, Before and After Emissions Shock, for 16 Individual Sessions

\begin{tabular}{lcc}
\hline \hline \multicolumn{3}{l}{ Uncorrelated Emission Shocks } \\
Sessions & Banking Allowed & No Banking \\
BUN1 \& NBUN1 & 8.71 & 25.24 \\
BUN2 \& NBUN2 & 4.08 & 15.35 \\
BUN3 \& NBUN3 & 5.70 & 22.04 \\
BUN4 \& NBUN4 & 6.23 & 7.63 \\
\cline { 2 - 3 } Treatment Mean & 6.18 & 17.56 \\
\hline \hline Correlated Emission Shocks & \\
Sessions & Banking Allowed No Banking \\
BCO1 \& NBCO1 & 5.85 & 31.90 \\
BCO2 \& NBCO2 & 11.31 & 20.15 \\
BCO3 \& NBCO3 & 12.74 & 33.75 \\
BCO4 \& NBCO4 & 12.09 & 24.72 \\
\cline { 2 - 3 } Treatment Mean & 10.50 & 27.63 \\
\hline \hline
\end{tabular}

Table 8: Average Coefficient of Variation in Transaction Prices, for 16 Individual Sessions

\begin{tabular}{lcc}
\hline \hline \multicolumn{3}{l}{ Uncorrelated Emission Shocks } \\
Sessions & Banking Allowed No Banking \\
BUN1 \& NBUN1 & 6.78 & 20.39 \\
BUN2 \& NBUN2 & 4.18 & 14.01 \\
BUN3 \& NBUN3 & 6.16 & 18.75 \\
BUN4 \& NBUN4 & 5.81 & 9.77 \\
\cline { 2 - 3 } Treatment Mean & 5.74 & 15.73 \\
\hline \hline Correlated Emission Shocks & \\
Sessions & Banking Allowed No Banking \\
BCO1 \& NBCO1 & 6.39 & 28.61 \\
BCO2 \& NBCO2 & 10.63 & 10.90 \\
BCO3 \& NBCO3 & 10.23 & 30.57 \\
BCO4 \& NBCO4 & 8.92 & 18.41 \\
\cline { 2 - 3 } Treatment Mean & 9.04 & 22.12 \\
\hline \hline
\end{tabular}


Table 9: Random Effects Regressions on Average Transaction Prices

\begin{tabular}{lccc}
\hline \hline & $(1)$ & $(2)$ & $(3)$ \\
Explanatory Variables & Pre-shock & Overall & $\begin{array}{c}\text { Post-shock } \\
\text { Prices }\end{array}$ \\
\hline Dummy for Banking & -1.0509 & 6.8513 & 17.1023 \\
& $(9.2052)$ & $(9.4307)$ & $(10.0266)$ \\
Dummy for Correlated Shocks & 3.6337 & 1.7805 & 0.4523 \\
& $(9.0766)$ & $(9.2994)$ & $(9.8534)$ \\
Magnitude of Aggregate Shocks & -0.1331 & 0.1560 & $0.5854^{*}$ \\
& $(0.2407)$ & $(0.2461)$ & $(0.2892)$ \\
Magnitude of Aggregate Shocks $\times$ & -0.0994 & $1.0928^{* *}$ & $2.4281^{* *}$ \\
Banking not allowed dummy & $(0.3333)$ & $(0.3409)$ & $(0.3991)$ \\
Amount Banked in Previous Period & $-0.5206^{* *}$ & $-0.6475^{* *}$ & $-0.9447^{* *}$ \\
& $(0.1368)$ & $(0.1399)$ & $(0.1635)$ \\
Constant & $106.3346^{* *}$ & $100.5616^{* *}$ & $93.2672^{* *}$ \\
& $(7.8673)$ & $(8.0603)$ & $(8.5408)$ \\
\hline Observations & 190 & 190 & 188 \\
Number of sessions & 16 & 16 & 16 \\
\hline \hline
\end{tabular}

Standard errors in parentheses

Denotes * significant at 5\%; ** significant at $1 \%$ 
Figure 1: Avoided Abatement Costs and Total Permits Available

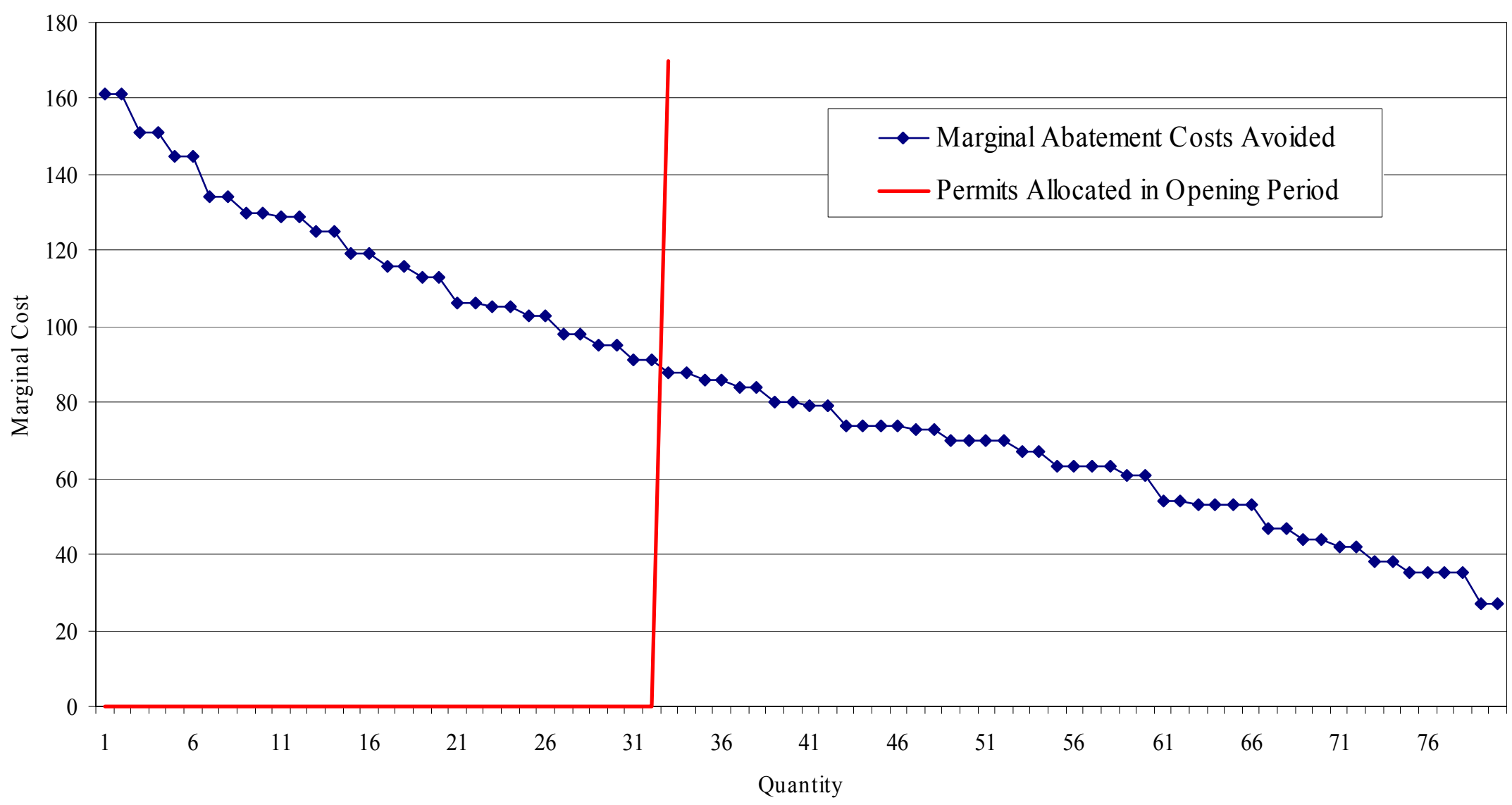


Figure 2: Transaction Prices for Session BUN3, with Banking and Uncorrelated Emissions Shocks

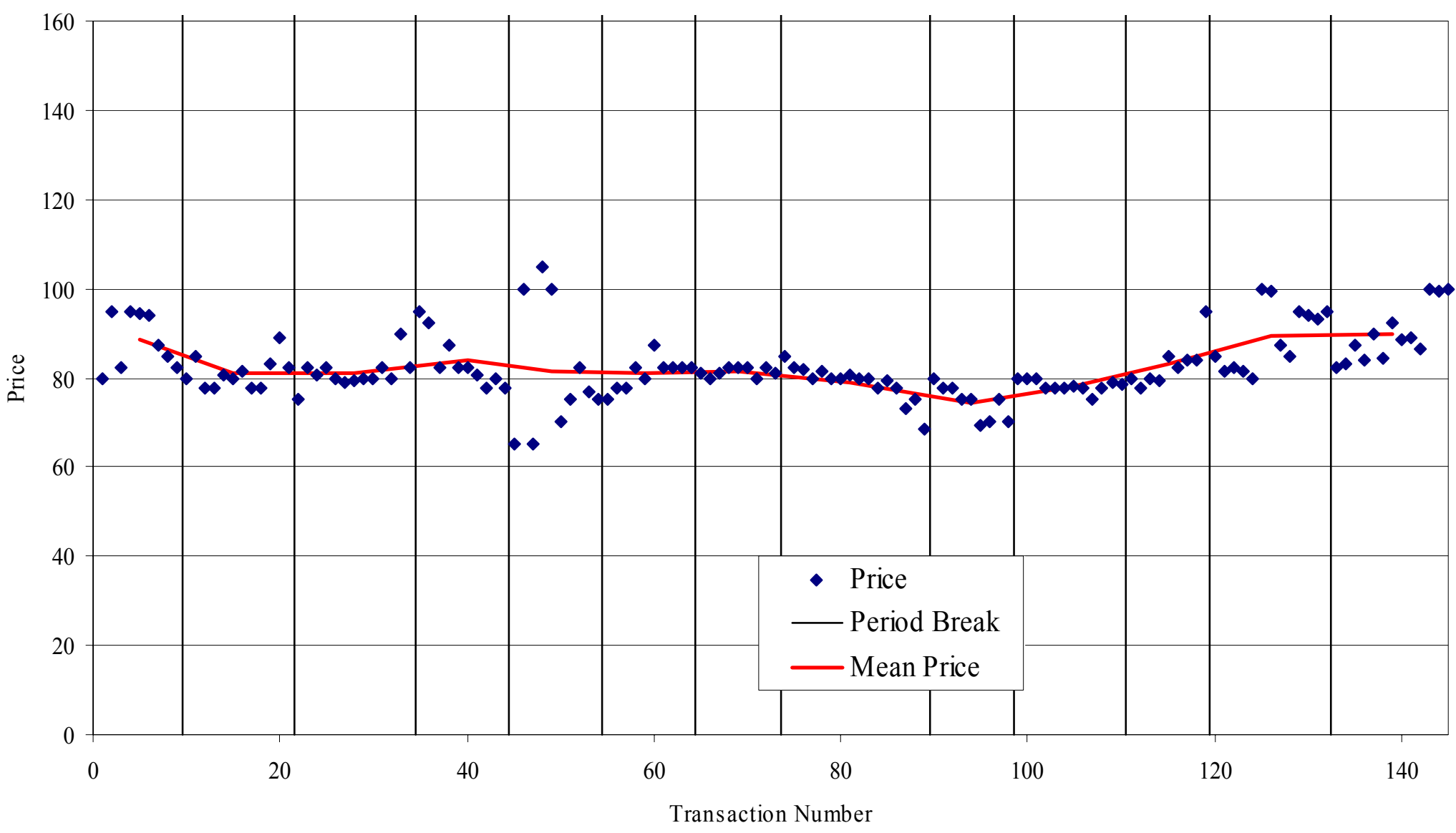


Figure 3: Transaction Prices for Session NBCO3, with No Banking and Correlated Emissions Shocks

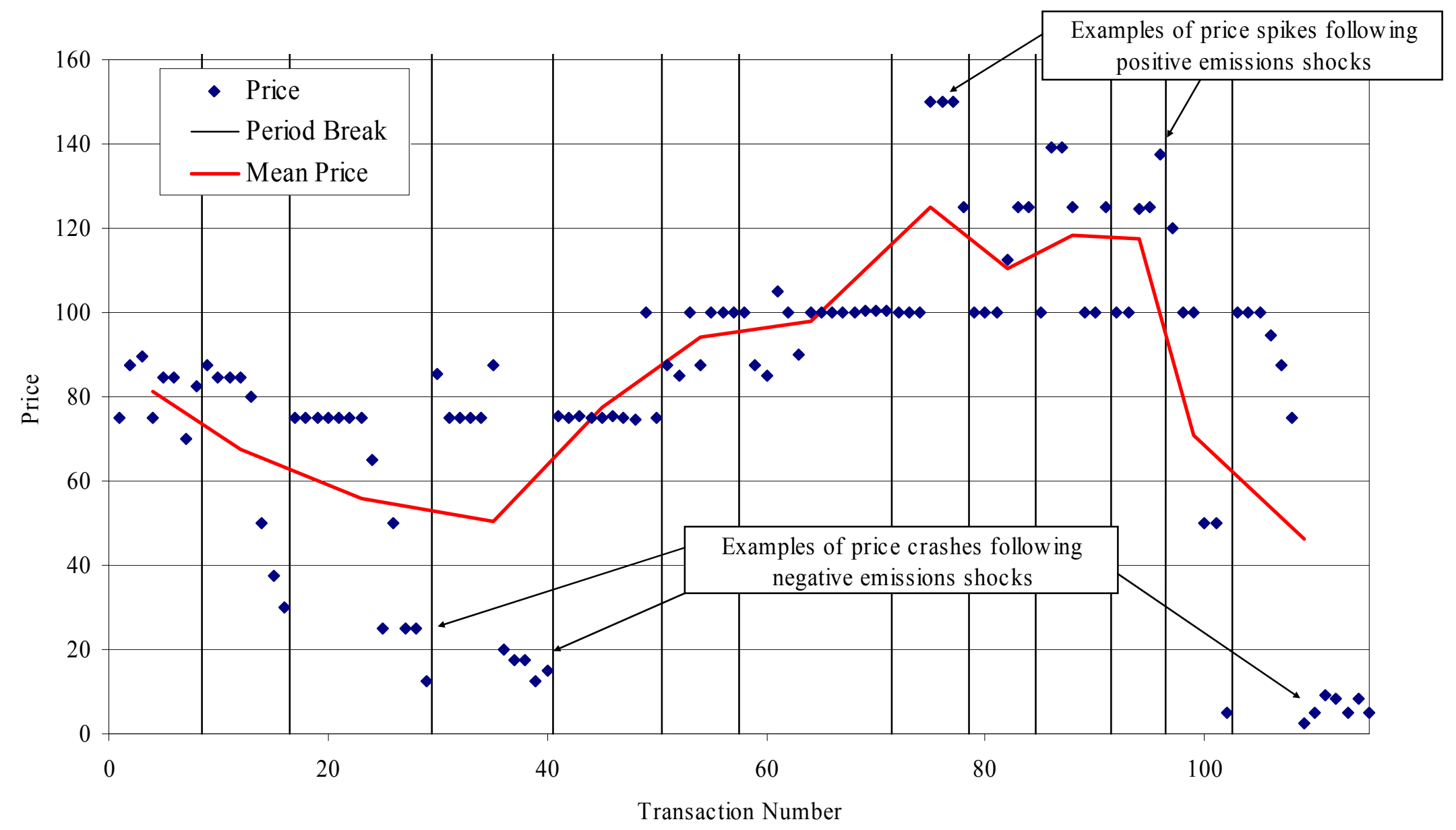


Figure 4: Emissions Shocks and Change in Average Permit Prices-All 8 Sessions with Banking Allowed

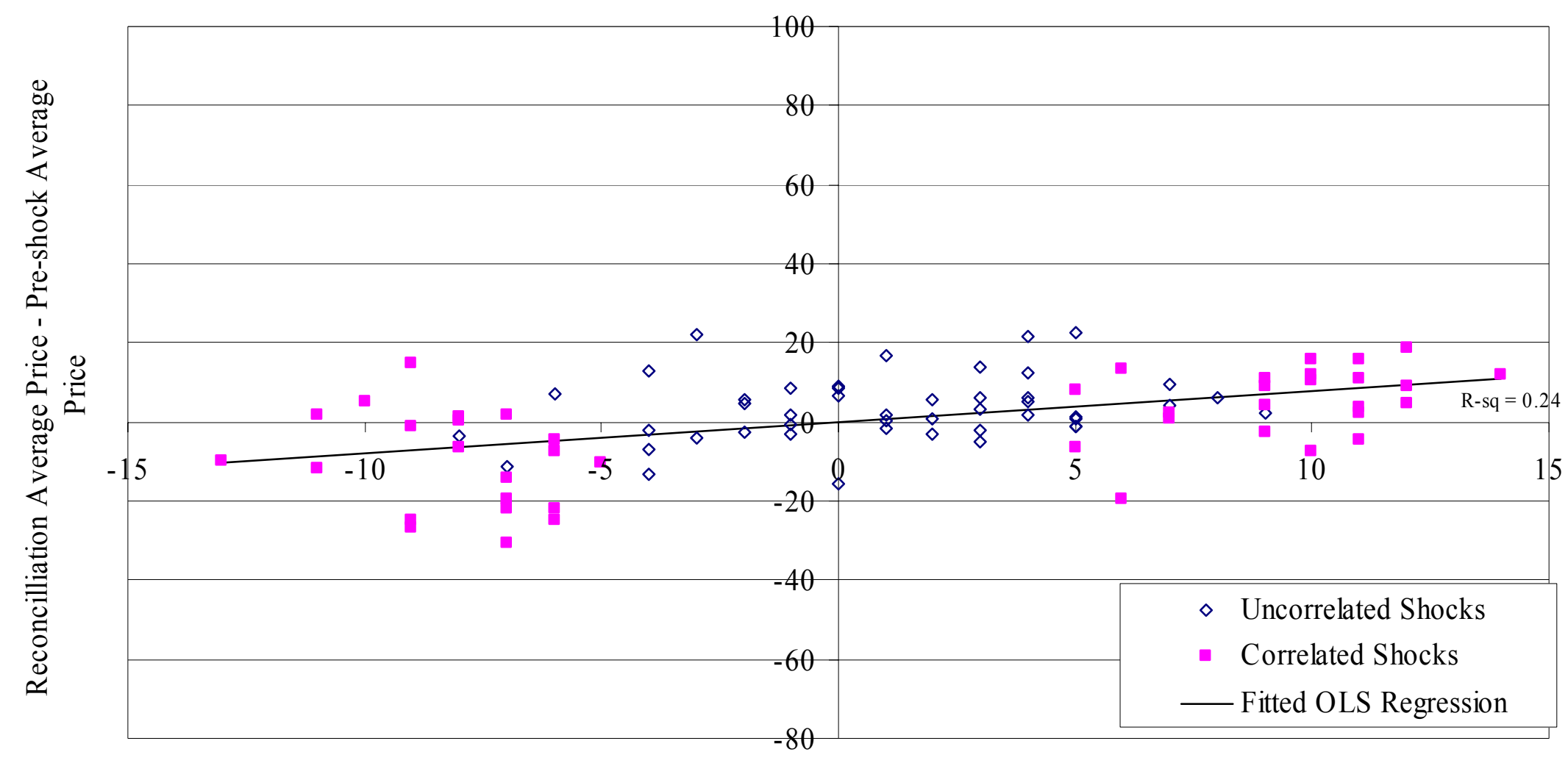

Aggregate Emissions Shock 
Figure 5: Emissions Shocks and Change in Average Permit Prices--All 8 Sessions with No Banking Allowed

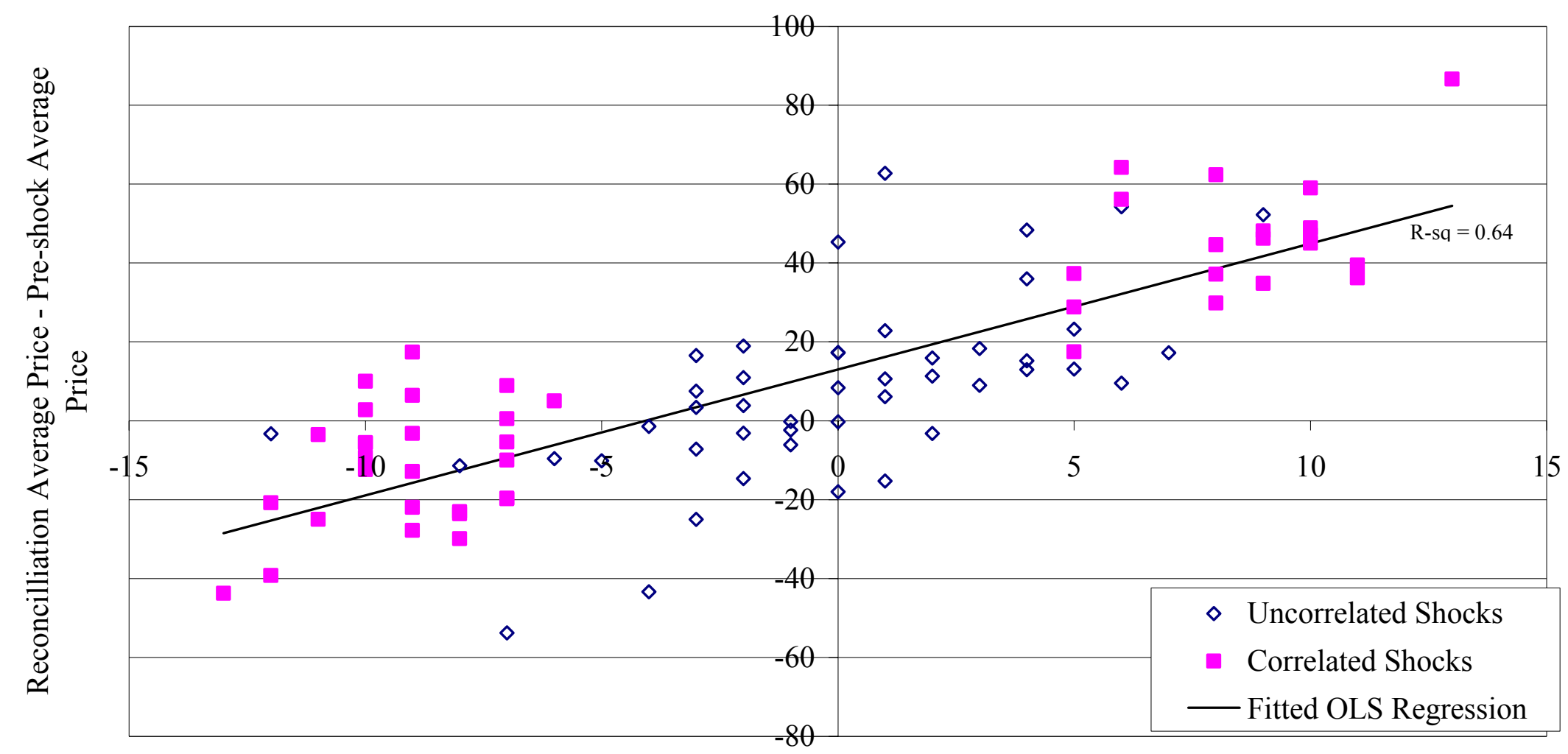

Aggregate Emissions Shock 


\section{Appendix-Experiment Instructions (Banking Allowed)}

\section{General}

This is an experiment in the economics of decision making. The instructions are simple and if you follow them carefully and make good decisions you will earn money that will be paid to you privately in cash. All earnings on your computer screens are in Experimental Dollars. These Experimental Dollars will be converted to real Dollars at the end of the experiment, at a rate of Experimental Dollars $=1$ real Dollar. Notice that the more Experimental Dollars that you earn, the more cash that you receive at the end of the experiment.

We are going to conduct a number of periods. You will not learn the number of periods until the end of the experiment. Attached to these instructions you will find a sheet labeled Personal Record Sheet, which will help you keep track of your earnings based on the decisions you might make. You are not to reveal this information to anyone. It is your own private information.

Each period is further subdivided into different stages. In some stages you will trade "coupons," and in other stages you will plan and report production levels. At the end of each

period you receive revenue, pay your production costs, and possibly pay fines. Your earnings each period are determined as follows:

\section{Earnings $=$ Fixed Period Revenue - Total Production Costs + Sale Proceeds from Selling Coupons - Amount Spent when Buying Coupons - Fines Paid.}

Your Fixed Period Revenue does not depend on any actions you take, and does not change throughout the experiment. (In fact, it is already written on your Personal Record Sheet.)

\section{Production Costs}

You must pay production costs when you produce units. The cost of each unit produced is typically different from the cost of other units produced, and your costs may or may not be different from the costs of other participants. Your production costs are always shown on the left side of your computer screen, as illustrated in Figure 1 (the numbers on this example screen are different from the actual numbers used in the experiment, and you won't actually learn your 
values until the experiment begins). Everyone can produce up to 10 units, and the cost of each unit is written separately.

For example, based on the numbers shown in the example in Figure 1, your first unit produced would cost 25 , your second unit produced would cost 35 , etc. If, for example, these were your production costs and you produced 3 units, your total costs would be $25+35+47=107$. So you must recognize that the costs shown on your screen are the extra costs associated with each additional unit produced.

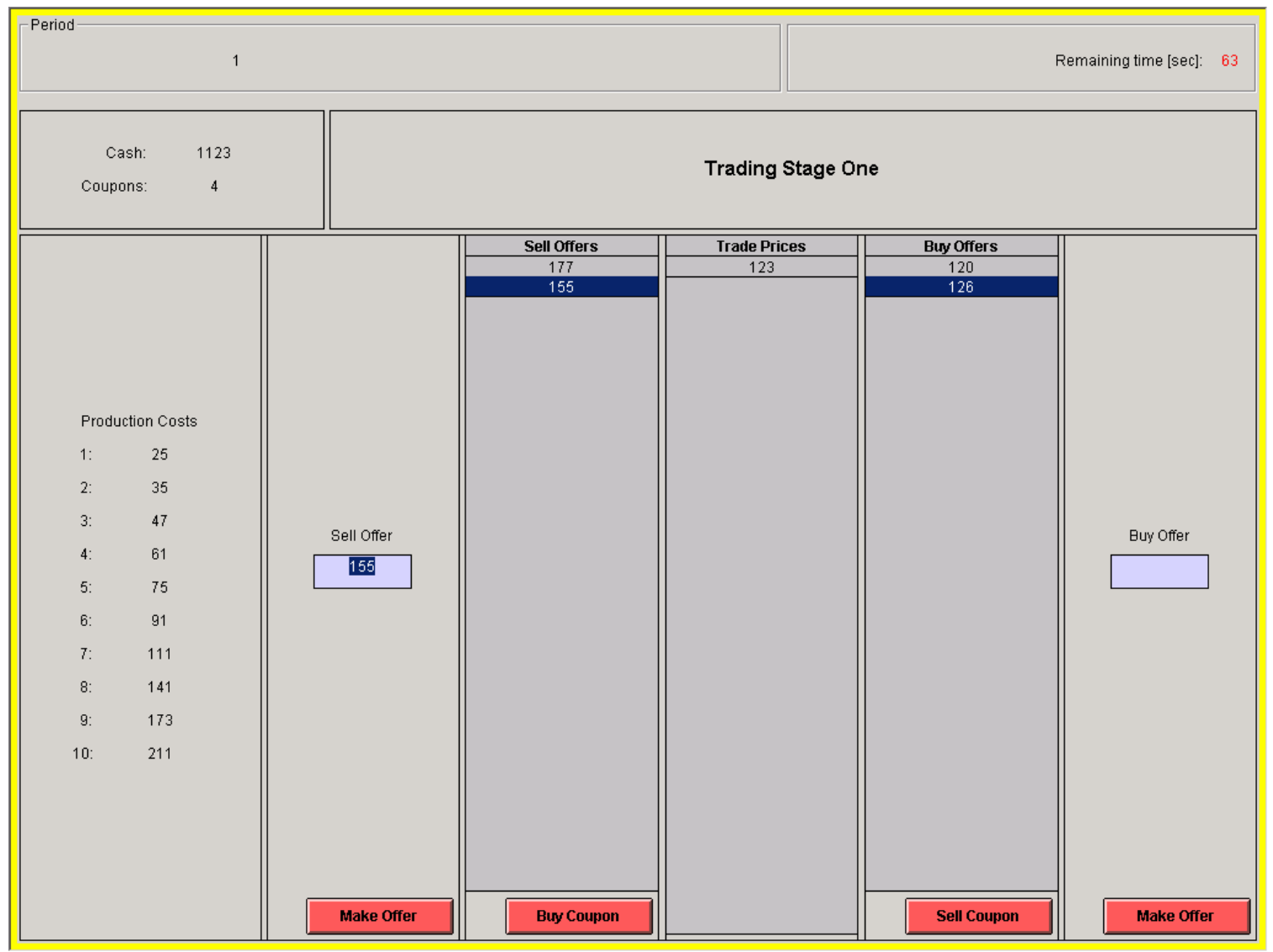

Figure 1

\section{Coupons}

We've already explained that your Fixed Period Revenue never changes, but your costs increase when you increase production. So why should you ever produce any units? The reason comes from today's compliance rule:

Compliance Rule: The sum of your production amount + coupons should equal at least 10 
This rule means that you can avoid production (and save on your production costs) by holding coupons. Everyone starts each period with some number of coupons, and anyone can adjust their own holding of coupons by buying and selling them in a market that will operate over the computer network. If you sell coupons your cash increases by the sale amount, and if you buy coupons your cash decreases by the sale amount. Later in these instructions we explain the rules for buying and selling coupons.

Why might you want to buy a coupon? Remember that coupons allow you to avoid production. If you currently hold 2 coupons, for example, and if you had the example production costs shown in Figure 1, then the last unit that you are supposed to produce is the $8^{\text {th }}$ unit (so that your production of $8+$ coupons of $2=10$ ). The production cost of this $8^{\text {th }}$ unit is 141 . So if you can buy a coupon for less than 141, this might be a good idea since it allows you to save the production cost of 141. For example, if you bought a coupon for 120, you save the production cost of 141 and therefore make a profit (because of the lower costs that you need to incur) of $141-120=21$.

Why might you want to sell a coupon? Continuing the illustration based on the example production costs shown in Figure 1, suppose that you currently hold 6 coupons. Then the last unit that you are supposed to produce is the $4^{\text {th }}$ unit (so that your production of $4+$ coupons of $6=$ 10). The production cost of your $5^{\text {th }}$ unit is 75 . So if you can sell a coupon for more than 75 , this might be a good idea since these sales revenues exceed the production costs of this $5^{\text {th }}$ unit. For example, if you sell a coupon for 120 , even if you incur the additional ( $5^{\text {th }}$ unit) production cost of 75 you would still make a profit on this sale of $120-75=45$.

\section{Target Production Choice}

In today's experiment, there will be a random element in the production of units, so that you have only incomplete control over your production level. In particular, as shown in Figure 2 you will be given an opportunity to set a target production level. But your actual production level may be up to 2 units higher or 2 units lower than your target. In particular, we will add a random value to your production target as follows:

Actual Production $=$ Target Production + Random Amount, 
where Random Amount takes a value of $-2,-1,0,1$ or 2, and each of these 5 possibilities are equally likely. Each participant in today's experiment will receive a random amount that is independent of anyone else's random amount. This means that your random amount is unrelated to anyone else's random amount in the current period, and it is unrelated to yours or anyone else's random amount in any previous or later period. You learn this random amount and your Actual Production in a screen like that shown in Figure 3.

You will have another opportunity to trade coupons after learning your Actual Production.

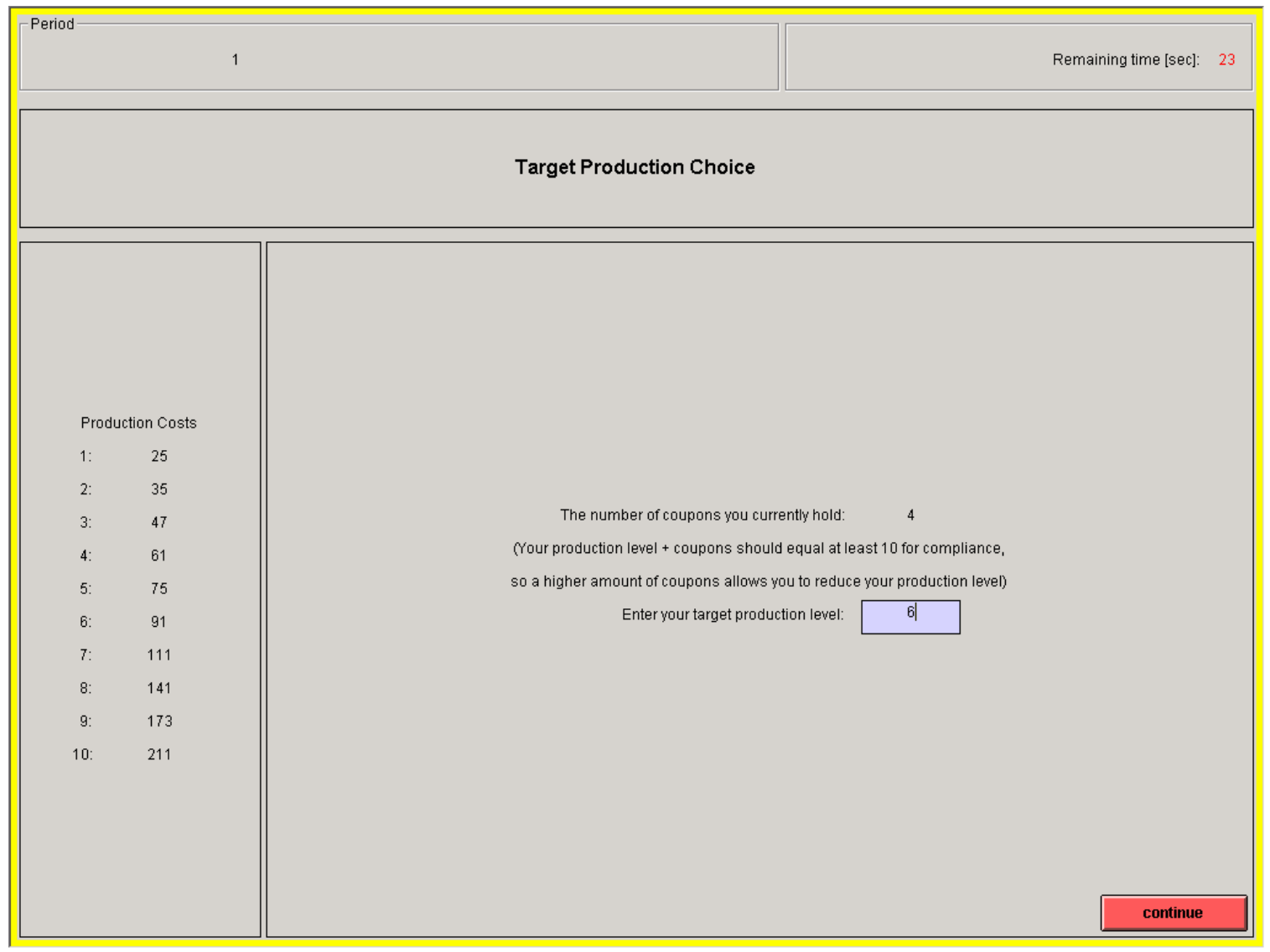

Figure 2 


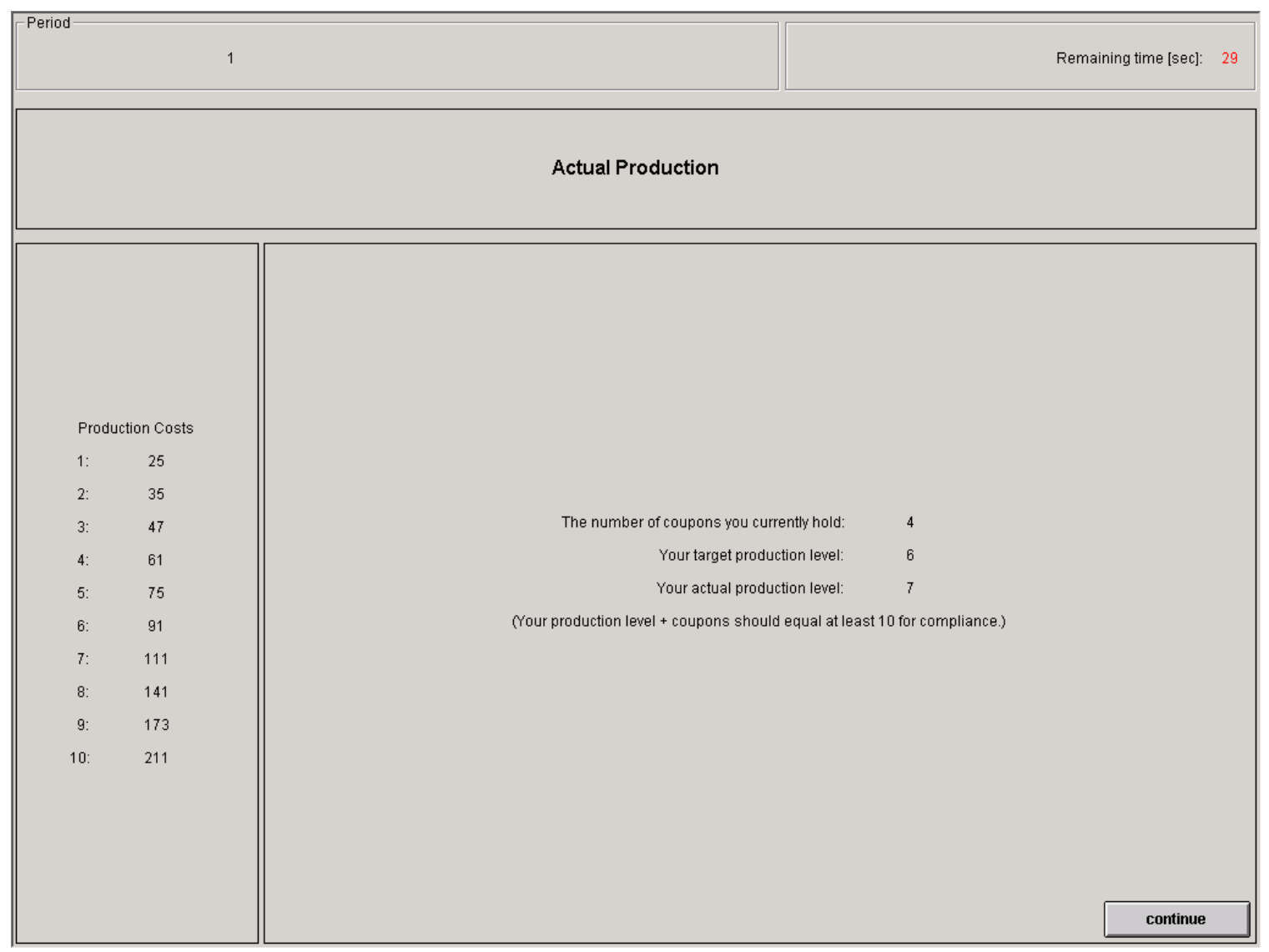

Figure 3

\section{Production Report and Fines}

Toward the end of each period, you will make a Production Report to an inspector, using a screen like that shown in Figure 4. What you must remember is the following:

The inspector always observes my coupon holdings.

The inspector does not observe my production amount unless he inspects me.

Your production costs depend on your Actual Production. You will choose how much production to report to the inspector. If he does not inspect you, then he takes your report as truthful and the number of coupons that you must use to meet the compliance obligation of production + coupons $\geq 10$ is based on your reported production. Please note that you are reporting production only, and not production + coupons. For example, if you hold 3 coupons and have 
actual production of 7 , if you wish to report this production accurately you report 7 , not 10, in your Production Report.

However, the inspector may inspect and determine your Actual Production. The probability (or, "likelihood") that he inspects depends on which Inspection Group you are currently in, as shown at the bottom of Figure 4. If he determines that your Actual Production differs from your reported production, then you will pay a fine based on how many units these two production levels differ. The size of the fine (per unit) also depends on which Inspection Group you are currently in, as shown at the bottom of Figure 4.

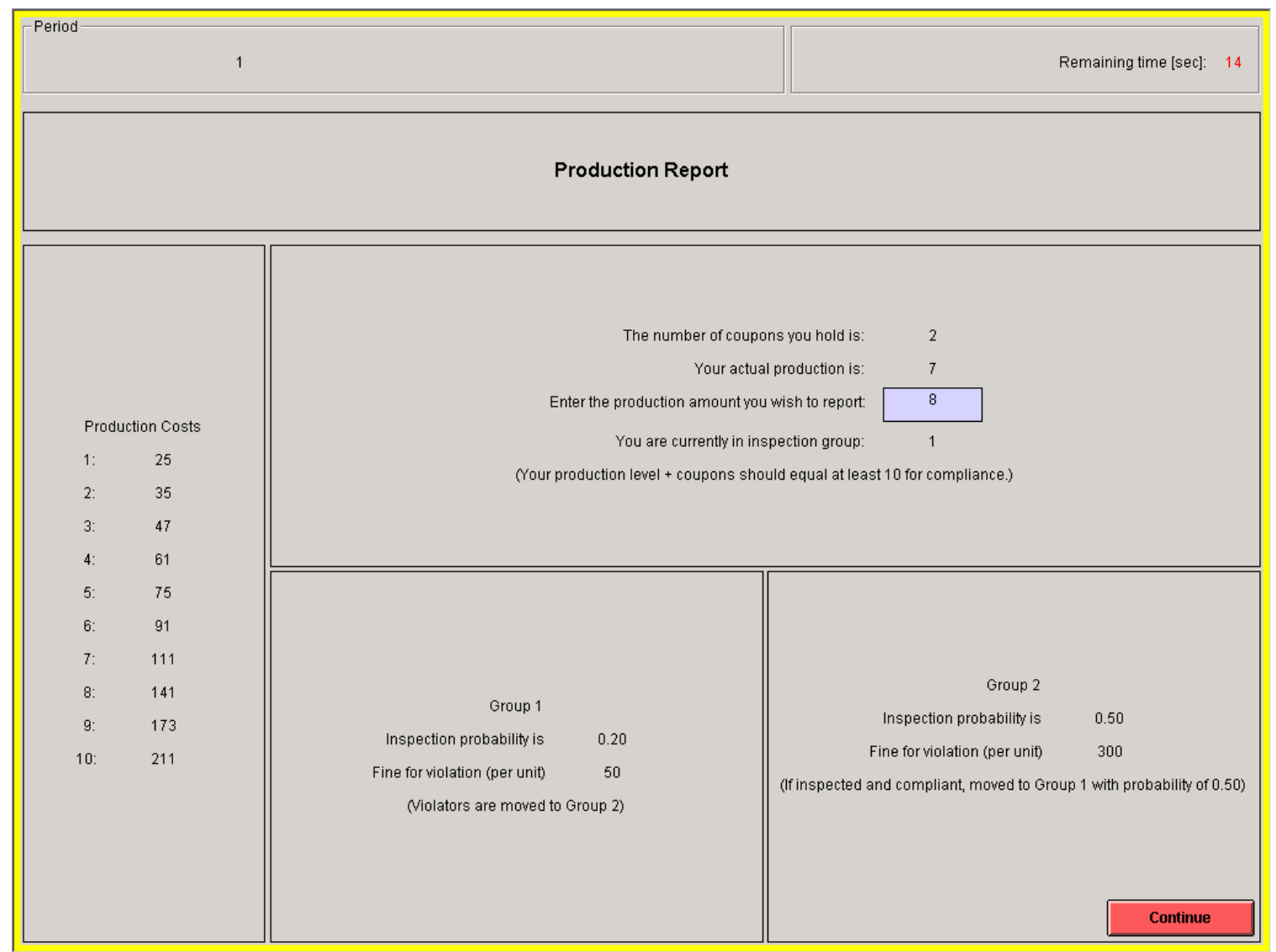

Figure 4

You could also be considered a violator and fined even if you are not inspected or are inspected and accurately report your production. This would occur if your reported production + coupons is less than 10 , because remember that they must sum to at least 10 for compliance. In this case, the fine paid is the per-unit fine times the amount that this sum falls below 10 . 
If you are in Inspection Group 1 and are determined to be in violation (in either of the manners just described), then you will automatically be moved to Inspection Group 2. If you are in Inspection Group 2 and are inspected and found to be in full compliance, then you may be moved back into Inspection Group 1. The probability that you are moved back to Group 1 is shown on the bottom right of your Production Report screen, shown in Figure 4.

Please remember that your production costs are calculated based on your Actual Production, not your Production Report or your Target Production.

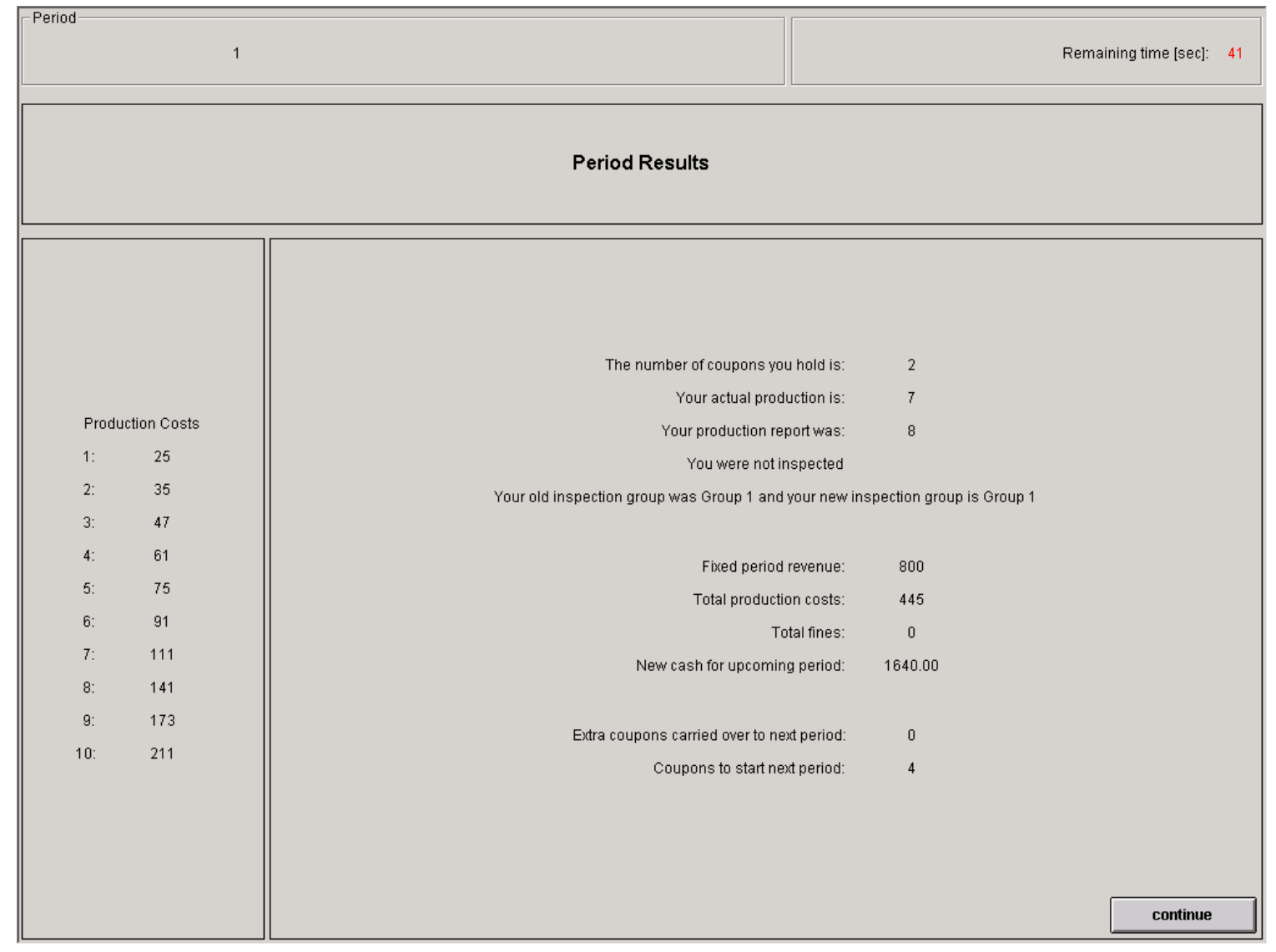

Figure 5

\section{Period Results and Carryover of Coupons to the Next Period}

Whether or not you are inspected and a summary of the results from the period are shown on the Period Results screen; Figure 5 presents an example. Your cash holdings are updated for the next period (and remember, these are the cash holdings that get converted into actual dollars 
at the end of the experiment). You should copy this information onto your Personal Record Sheet at the end of each period, and then click "continue" to begin the next period.

The bottom of this screen shows how your coupons to start the next period are updated based on what happened in the period that just ended. If you were not inspected, and if the number of coupons you hold + your production report is greater than 10, you can "carry over" the extra coupons to the next period. (As already noted in these instructions, everyone starts each new period with a number of "starting" coupons. This new allocation of coupons each period does not change in different periods) If you were inspected, and if the number of coupons you hold + your actual production is greater than 10 , you can carry over the extra coupons to the next period. For example, suppose that you hold 7 coupons, and your actual production is 5 (and your Reported Production is also 5 and you were inspected). Since your coupons + production $=12>10$, you can "carry over" these 2 extra coupons to the next period. Of course, at the end of the experiment there is not next period so any extra coupons are not useful.

On the other hand, if the number of coupons you hold + your production (either actual or reported, depending on whether you were inspected) is less than 10, in addition to paying a fine the number of coupons that you have to start the next period is reduced by the amount that this sum falls below 10. For example, if you hold 3 coupons and your production is 5 , this sum of $8<10$. You would pay 2 times the per-unit fine for your Inspection Group, and your starting coupons for the next period would be reduced by 2 .

\section{How to Buy and Sell}

Each trading period will have two trading stages, and each trading stage will be open for trading for 2 or 3 minutes. Trading Stage One occurs before you set a production target and learn your actual production, and the Final Trading Stage occurs after you learn your actual production At any time during either trading stage, everyone is free to make an offer to buy a coupon at a price they choose; likewise, everyone is free to make an offer to sell a coupon at a price they choose. Also at any time during the period, everyone is free to buy at the best offer price specified by someone wishing to sell, and everyone is free to sell at the best offer price specified by someone wishing to buy. (Of course, there are some limits: to sell a unit or make a sales offer, you need to have a coupon to sell. And to buy a unit or make a buy offer, you need to have enough cash to pay.) 
You will enter offer prices and accept prices to execute transactions using your computer. Figure 1 shows the market trading screen for Stage One trading. The time left in the period is shown on the upper right of the trading screen. Participants interested in buying can submit offer prices using the "Buy Offer" box in the right side of the screen, and then clicking on the "Make Offer" button in the lower right. This offer price is immediately displayed on all traders' computers on the upper right part of the screen, labelled "Buy Offers." Once this offer price has been submitted, it is binding in the sense that anyone wishing to sell can accept this price offer. Such an acceptance results in an immediate trade at that price. The previous trading prices in the current period are displayed in the "Trading Prices" list in the center of your computer screen.

If there are already Buy Offers displayed in the current period, then new buy offers submitted by anyone wishing to buy must provide better trading terms to the sellers. Sellers prefer higher prices, so any new buy offers must be higher than the current highest buy offer. Your computer will give you an error message if you try to offer a lower price than the best price currently available.

Anyone wishing to buy can accept the best (that is, lowest sell offer price) by simply clicking the "Buy Coupon" button on the bottom of their computer screen. This results in an immediate trade at that price.

Participants interested in selling can submit offer prices using the "Sell Offer" box on the left side of the screen, and then clicking on the "Make Offer" button below this box. This offer price is immediately displayed on all traders' computers on the left part of the screen, labelled "Sell Offers." Once this offer price has been submitted, it is binding in the sense that anyone wishing to buy can accept this price offer. Such an acceptance results in an immediate trade at that price.

If there are already Sell Offers displayed in the current period, then new sell offers submitted by anyone wishing to sell must provide better trading terms to the buyers. Buyers prefer lower prices, so any new sell offers must be lower than the current lowest sell offer. Your computer will give you an error message if you try to offer a higher price than the best price currently available.

Anyone wishing to sell can accept the best (that is, highest offer price) by simply clicking the "Sell Coupon" button on the bottom of their computer screen. This results in an immediate trade at that price. 


\section{Summary}

- Your production costs shown on the left of your computer screen are the extra, additional costs incurred for each unit that you produce.

- To be in compliance, you are supposed to have the sum of your production + coupons $\geq 10$.

- Your actual production may differ from your target production by as much as +2 or -2 units.

- The inspector always observes your coupon holdings, but the inspector does not observe your production amount unless he inspects you.

- You pay per unit fines that depend on how much the sum of your coupons + production (either actual or reported depending on whether you were inspected) is less than 10, or when you are inspected and your actual and reported production do not match.

- You may move between the different Inspection Groups depending on your reporting decisions and whether or not you were inspected.

- Extra coupons that you don't need in the current period are carried over to the next period, and any shortfall in coupons in the current period reduces your next period allocation of coupons by the shortfall amount.

Before we begin making decisions for real money, we will conduct one practice period for you to get comfortable with the trading software, and to make one production target and reporting decision. This practice period does not affect your experiment earnings. Once we begin the experiment you should be careful to maintain positive cash holdings, since anyone whose end-ofperiod cash is below zero for 3 consecutive periods will be considered bankrupt and will no longer be allowed to participate in the experiment.

Are there any questions now before we begin the practice period? 
Review of key points from the Instructions, and some new additional information (Distributed and read aloud when subjects return for their "data" session-usually in the week following their training session - after they have a chance to privately review the full, detailed instructions.)

1. Your computer screen displays the extra, additional production costs that you pay for each unit produced. The production costs that you pay are based on your actual, not your reported, production.

2. Holding coupons allows you to avoid production. For compliance, you are supposed to have the sum of your production + coupons $\geq \mathbf{1 0}$.

3. Each period you will enter a production target, but your actual production may differ from your target: Actual Production = Target Production + Random Amount. The Random Amount can be -2, -1, 0, 1, or 2. In today's experiment, in a particular period every participant will have random amounts of $-2,-1$ or 0 , or every participant will have random amounts of 0,1 or 2 . There is an equal chance each period that everyone has nonpositive or nonnegative random amounts, there is a 20 percent chance of 0,40 percent chance of -1 or +1 , and a 40 percent chance of -2 or +2 . Within the set of nonpositive or nonnegative amounts, your random amount is drawn independently from other participants' random amounts, and independently from period to period.

4. The inspector always observes your coupon holdings, but he does not observe your actual production unless he inspects you. You make a Production Report each period.

5. If you are not inspected, the inspector will simply check whether your Production Report + coupons $\geq 10$. If this sum is less than 10 , then you pay a fine for each unit below 10, and the coupons you start the next period with are reduced by the amount the sum falls below 10. If this sum is greater than 10, then you are not fined and you can carry over these "unused" coupons to the next period.

6. If you are inspected, the inspector will check whether your Actual Production + coupons $\geq 10$, and also whether your Production Report $=$ Actual Production. If the Actual Production + coupons sum is less than 10, then you pay a fine for each unit below 10, and the coupons you start the next period with are reduced by the amount this sum falls below 10. If this sum is greater than 10, then you are not fined and you can carry over these "unused" coupons to the next period. You will also be fined if your Production Report $>$ Actual Production, and you pay a fine for each unit that these amounts differ. You will pay the maximum fine calculated by these two methods.

7. There are two inspection groups. If you pay a fine for any type of violation while in Group 1, you automatically move to Group 2. If you are inspected while in Group 2 
and are found to be in full compliance, then you are automatically moved back into Group 1. Everyone starts the experiment in Group 1.

8. The chances of being inspected and the per-unit fines for violations differ in the two groups, as shown in the following table. These inspection rates and fines do not change during the entire experiment.

\begin{tabular}{|l|l|}
\hline Inspection Group 1 & Inspection Group 2 \\
\hline Inspection Probability $=0.3$ & Inspection Probability $=0.5$ \\
\hline Fine for violation (per unit) $=60$ & Fine for violation (per unit) $=150$ \\
\hline Violators are moved to Group 2 & If inspected and compliance, moved to Group 1 \\
\hline
\end{tabular}

9. Everyone starts the experiment with some initial cash holdings, and each period everyone receives additional fixed period revenue (added to their cash) and some additional coupons. The additional cash and coupons added to your account do not change across periods, and the amounts are already shown on your Personal Record Sheet. You should be careful to maintain positive cash holdings (in the "New Cash" column of your Record Sheet), since anyone whose end-of-period cash is below zero for 3 consecutive periods will be considered bankrupt and will no longer be allowed to participate in the experiment.

10. The end period of today's experiment is determined randomly. We will conduct 8 periods with certainty, and then after the $8^{\text {th }}$ period and for every later period the experimenter rolls a 6-sided die. If this die roll comes up " 6 " then the experiment ends immediately; otherwise, we will continue for another period. The die is rolled again in each subsequent period, and the experiment will not end until we roll a 6 at the end of some period. These die rolls already occurred in Professor Cason's office before the experiment. The experimenter will reveal the outcome of each single roll at the end of each period beginning after the $8^{\text {th }}$ period.

11. Experimental dollars will be converted to real Dollars at the end of the experiment, at a rate of 300 Experimental Dollars $=1$ real Dollar. Notice that the more Experimental Dollars that you earn, the more cash that you receive at the end of the experiment 
Quiz: Please circle the correct answer. Do not put your name on the quiz.

1. Suppose that you have the Production Costs shown in the Figure 1 example of the main instructions. If your Actual Production is 3 units and your Reported Production is 4 units, what are your total production costs for all your units produced?
(a) 47
(b) 61
(c) 107
(d) 168

2. Again use the Production Costs example shown in Figure 1, and suppose that you wish to exactly meet the compliance target of Production + Coupons $=10$. If you currently hold 3 coupons and you buy a $4^{\text {th }}$ coupon, how much in Production Costs have you just potentially saved?
(a) 141
(b) 111
(c) 61
(d) 47

3. If you set a Target Production of 5, which of the following CANNOT be your Actual Production?
(a) 2
(b) 5
(c) 6
(d) 7

4. Suppose your Actual Production is 7 and you hold 4 coupons. To be fully in compliance you must make a Production Report of
(a) 10
(b) 4
(c) 6
(d) 7
(e) I cannot be in compliance with any report

5. Suppose your Actual Production is 5 and you hold 4 coupons. To be fully in compliance you must make a Production Report of
(a) 10
(b) 4
(c) 6
(d) 5
(e) I cannot be in compliance with any report

6. Suppose your Production Report is 7, your Actual Production is 4, and you hold 5 coupons. You are in Inspection Group 1.

A. If you are not inspected, then

(a) you are fined 180 and your allocation of coupons in the next period is reduced by 3 .

(b) you are fined 60 and your allocation of coupons in the next period is not affected.

(c) you are not fined but your allocation of coupons in the next period is reduced by 1.

(d) you are not fined and you can carry over 2 coupons into the next period.

B. If you are inspected, then 
(a) you are fined 180 and your allocation of coupons in the next period is reduced by 3.

(b) you are fined 60 and your allocation of coupons in the next period is reduced by 1.

(c) you are fined 180 and your allocation of coupons in the next period is reduced by 1.

(d) you are not fined and your allocation of coupons in the next period is not affected.

7. Suppose your Actual Production is 8 and you hold 4 coupons. If you are in Inspection Group 2, how can you move back to Inspection Group 1?

(a) Report Production of 8 and be inspected.

(b) Report Production of 6 and be inspected.

(c) Report Production of 8 and hope that you are not inspected.

(d) Report Production of 10 and hope that you are not inspected.

8. Suppose you hold 4 coupons and your Actual Production is 8. If you Report Production of 9 then

(a) you carry over 2 coupons into the next period regardless of whether or not you are inspected.

(b) you carry over 2 coupons into the next period if you are inspected and you carry over 3 coupons into the next period if you are not inspected.

(c) you carry over 2 coupons into the next period if you are inspected and you carry over 1 coupon into the next period if you are not inspected.

(d) you carry over 3 coupons into the next period if you are inspected and you carry over 2 coupons into the next period if you are not inspected. 


\section{References}

Ben-David, S., D. Brookshire, S. Burness, M. McKee and C. Schmidt. (2000) Attitudes Toward Risk and Compliance in Emission Permit Markets, Land Economics 76, pp. 590-600.

Cason, T. and L. Gangadharan (2004) An Experimental Study of Compliance and Leverage in Auditing and Regulatory Enforcement, Mimeo, Purdue University.

Cronshaw, M. and J. Brown Kruse (1999) An Experimental Analysis of Emissions Permits with Banking and the Clean Air Act Amendments of 1990 in Research in Experimental Economics, vol. 7, C. Holt and R. M. Isaac (eds.), Stamford, Conn.: JAI Press, pp. 1-24.

Eckert, H. (2004) Inspections, Warnings and Compliance: The Case of Petroleum Storage Regulation. Journal of Environmental Economics and Management, 47, Pages 232-259.

Fischbacher, U. (1999) z-Tree - Zurich Toolbox for Readymade Economic Experiments, Working Paper No. 21, Institute for Empirical Research in Economics, University of Zurich.

Godby, R., S. Mestelman, R.A. Muller and J. D. Welland (1997) Emissions Trading with Shares and Coupons when Control of Discharges is Uncertain. Journal of Environmental Economics and Management, 32, Pages 359-381.

Greenberg, J (1984) Avoiding Tax Avoidance: A (Repeated) Game-theoretic Approach. Journal of Economic Theory, 32(1), Pages 1-13.

Harrington, W (1988) Enforcement Leverage When Penalties are Restricted. Journal of Public Economics 37, Pages 29-53.

Innes, R. (2003) Stochastic Pollution, Costly Sanctions, and Optimality of Emission Permit Banking. Journal of Environmental Economics and Management, 45, Pages 546-568.

Kling, C. and J. Rubin (1997) Bankable Permits for the Control of Environmental Pollution. Journal of Environmental Economics and Management 65, Pages 101-115.

Landsberger, M and I. Meilijson (1982) Incentive Generating State Dependent Penalty System: The case of Income Tax Evasion. Journal of Public Economics, 19, Pages 333-352.

Malik, A. (1990) Markets for Pollution Control when Firms are Noncompliant. Journal of Environmental Economics and Management, 18, Pages 97-106.

Mestelman, S., R. Moir and R. A. Muller (1999) A Laboratory Test of a Canadian Proposal for an Emissions Trading Program, in Research in Experimental Economics, vol. 7, C. Holt and R. M. Isaac (eds.), Stamford, Conn.: JAI Press, Pages. 45-92. 
Murphy, J. and J. Stranlund (2004) Direct and Market Effects of Enforcing Emissions Trading Programs: An Experimental Analysis. Mimeo, University of Massachusetts-Amherst.

Raymond, M. (1999) Enforcement Leverage when Penalties are Restricted: A Reconsideration under Asymmetric Information. Journal of Public Economics, 73, Pages 289-295.

Stranlund, J. and K.K. Dhanda (1999) Endogenous Monitoring and Enforcement of a Transferable Emissions Permit System. Journal of Environmental Economics and Management, 38, Pages 267-282. 


\section{University Library}

\section{- M M I E R R V A gateway to Melbourne's research publications}

Minerva Access is the Institutional Repository of The University of Melbourne

Author/s:

Cason, Timothy;GANGADHARAN, LATA

Title:

Emissions variability in tradable permit markets with imperfect enforcement and banking

Date:

2004-09

Citation:

Cason, Timothy and Gangadharan, Lata (2004) Emissions variability in tradable permit markets with imperfect enforcement and banking.

Persistent Link:

http://hdl.handle.net/11343/34296 